\title{
Loss of CDKL5 in Glutamatergic Neurons Disrupts Hippocampal Microcircuitry and Leads to Memory Impairment in Mice
}

\author{
[DSheng Tang, ${ }^{1,2,3}$ I-Ting Judy Wang, ${ }^{1}$ Cuiyong Yue, ${ }^{3}$ Hajime Takano, ${ }^{2,3}$ Barbara Terzic, ${ }^{1}{ }^{\circ}$ Katarina Pance, ${ }^{1}$ \\ 이 Yun Yee, ${ }^{1}$ ㄴ)Yue Cui, ${ }^{1}$ Douglas A. Coulter, ${ }^{2,3}$ and Zhaolan Zhou ${ }^{1}$ \\ ${ }^{1}$ Department of Genetics and ${ }^{2}$ Departments of Neuroscience, Neurology, and Pediatrics, University of Pennsylvania Perelman School of Medicine, \\ and ${ }^{3}$ The Research Institute of the Children's Hospital of Philadelphia, Philadelphia, Pennsylvania 19104
}

Cyclin-dependent kinase-like 5 (CDKL5) deficiency is a neurodevelopmental disorder characterized by epileptic seizures, severe intellectual disability, and autistic features. Mice lacking CDKL5 display multiple behavioral abnormalities reminiscent of the disorder, but the cellular origins of these phenotypes remain unclear. Here, we find that ablating CDKL5 expression specifically from forebrain glutamatergic neurons impairs hippocampal-dependent memory in male conditional knock-out mice. Hippocampal pyramidal neurons lacking CDKL5 show decreased dendritic complexity but a trend toward increased spine density. This morphological change is accompanied by an increase in the frequency of spontaneous miniature EPSCs and interestingly, miniature IPSCs. Using voltage-sensitive dye imaging to interrogate the evoked response of the CA1 microcircuit, we find that CA1 pyramidal neurons lacking CDKL5 show hyperexcitability in their dendritic domain that is constrained by elevated inhibition in a spatially and temporally distinct manner. These results suggest a novel role for CDKL5 in the regulation of synaptic function and uncover an intriguing microcircuit mechanism underlying impaired learning and memory.

Key words: CDKL5; circuit function; learning and memory; synaptic function

Significance Statement

Cyclin-dependent kinase-like 5 (CDKL5) deficiency is a severe neurodevelopmental disorder caused by mutations in the CDKL5 gene. Although $C d k l 5$ constitutive knock-out mice have recapitulated key aspects of human symptomatology, the cellular origins of CDKL5 deficiency-related phenotypes are unknown. Here, using conditional knock-out mice, we show that hippocampaldependent learning and memory deficits in CDKL5 deficiency have origins in glutamatergic neurons of the forebrain and that loss of CDKL5 results in the enhancement of synaptic transmission and disruptions in neural circuit dynamics in a spatially and temporally specific manner. Our findings demonstrate that CDKL5 is an important regulator of synaptic function in glutamatergic neurons and serves a critical role in learning and memory.

\section{Introduction}

Cyclin-dependent kinase-like 5 (CDKL5) deficiency is characterized by early-onset epilepsy, severe intellectual disability, autistic

\footnotetext{
Received Feb. 25, 2017; revised June 15, 2017; accepted June 22, 2017.

Author contributions: S.T., I.T.W., C.Y., H.T., D.A.C., and Z.Z. designed research and analyzed data; S.T., I.T.W., C.Y., B.T., K.P., J.Y.L., and Y.C. performed research; and S.T. and I.T.W. wrote the paper with input from all other authors.

This work was supported by The Loulou Foundation (Z.Z.), International Foundation for CDKL5 Research (Z.Z.), the Intellectual and Developmental Disabilities Research Center (IDDRC) at CHOP/PENN 1U54HD086984 (D.A.C.), 4R01NS038572 (D.A.C.), 5 T32MH017168 (I.T.W.), T32HD083185 (S.T.), T32GM007170 (S.T.), F30NS100433 (S.T.), and the Hearst Foundation Fellowship (S.T.). Z.Z. is a Pew scholar in biomedical sciences. We thank the University of Pennsylvania Neurobehavioral Core (Dr. Timothy 0'Brien) and Cell and Developmental Biology Microscopy Core (Dr. Andrea Stout) for providing training and resources, and the Biostatistics and Bioinformatics Core at CHOP/PENN (Dr. Mary Putt) for assistance with statistical analysis.

The authors declare no competing financial interests.
}

features, and various comorbidities (Kalscheuer et al., 2003; Weaving et al., 2004; Bahi-Buisson and Bienvenu, 2012; Fehr et al., 2016). It is caused by mutations in the X-linked gene, CDKL5, a member of a highly conserved family of serine-threonine kinases (Kilstrup-Nielsen et al., 2012). Mice that constitutively lack CDKL5 recapitulate several key features of the disorder, including impaired hippocampal-dependent memory, deficits in motor coordination, and autistic-like phenotypes such as reduced socia-

Correspondence should be addressed to either of the following: Dr. Zhaolan Zhou, Room 450, Clinical Research Building, 415 Curie Boulevard, Philadelphia, PA 19104, E-mail: zhaolan@mail.med.upenn.edu; or Douglas A. Coulter, Room 410D, Abramson Pediatric Research Building, 3516 Civic Boulevard, Philadelphia, PA 19104, E-mail: coulterd@email.chop.edu.

DOI:10.1523/JNEUROSCI.0539-17.2017

Copyright $\odot 2017$ the authors $\quad 0270-6474 / 17 / 377420-18 \$ 15.00 / 0$ 
bility and increased repetitive behavior (Wang et al., 2012). However, the cellular origins and circuit mechanisms contributing to these phenotypes have yet to be identified, thus limiting the insight into the pathogenic mechanisms that underlie CDKL5 deficiency.

Cdkl5 mRNA and protein expression is highly enriched in neurons of the forebrain (Lein et al., 2007; Wang et al., 2012), where glutamatergic and GABAergic cell types predominate (Hébert and Fishell, 2008; Poulin et al., 2016). In excitatory neurons, CDKL5 has been found to localize to the postsynaptic density, where it interacts with postsynaptic density protein 95 (PSD-95), netrin-G1 ligand (NGL-1), and Rac1 (Chen et al., 2010; Ricciardi et al., 2012; Zhu et al., 2013). CDKL5 knockdown or constitutive knock-out result in changes in the dendritic branching, spine density, and synaptic function of glutamatergic neurons (Chen et al., 2010; Ricciardi et al., 2012; Zhu et al., 2013; Sala et al., 2016). However, the directionality of these changes appears to be highly contextdependent. For example, shRNA-mediated knockdown of CDKL5 in cultured mouse hippocampal neurons leads to an increase in immature spine numbers (Ricciardi et al., 2012), whereas downregulation of CDKL5 by the in utero electroporation of an shRNA construct in the rat reduces overall spine density (Zhu et al., 2013). In adult Cdkl5 constitutive knock-out mice, both spine stability and spine density are reduced in the somatosensory cortex (Sala et al., 2016). Given that CDKL5 is also expressed in GABAergic neurons (Rusconi et al., 2008; Johnson et al., 2017), the extent to which these cellular and morphological phenotypes are the result of cell-autonomous dysfunction in excitatory neurons or a consequence of loss of CDKL5 in GABAergic neurons remain unknown. Furthermore, how these cellular phenotypes contribute to functional deficits at the synapse, circuit, and even behavioral level remains to be determined.

Given that CDKL5 is highly expressed in excitatory neurons and is localized to the postsynaptic density of excitatory synapses, we performed conditional knock-out studies of CDKL5 in excitatory neurons and set out to (1) determine the contribution of excitatory neuronal dysfunction to behavioral abnormalities in CDKL5 deficiency, (2) investigate how CDKL5 loss affects dendrite and spine morphology in vivo in mice, and (3) examine the resulting synaptic and circuit dysfunction in a behaviorally relevant microcircuit. We find that loss of CDKL5 in forebrain excitatory neurons impairs hippocampal-dependent memory and alters neuronal morphology. In addition, hippocampal pyramidal neurons lacking CDKL5 show enhanced spontaneous synaptic activity, evidenced by the elevation of mEPSC and mIPSC frequency. Interestingly, the alteration of synaptic excitation and inhibition leads to a complex, layer-specific disruption of CA1 microcircuit dynamics. Our findings suggest a glutamatergic neuron-specific mechanism for learning and memory impairment in CDKL5 deficiency and reveal a novel role for CDKL5 in regulating synaptic and circuit function in vivo.

\section{Materials and Methods}

Generation of Cdkl5 conditional knock-out mice. An identical targeting construct and strategy was used from the generation of $C d k l 5$ constitutive knock-out mice (Wang et al., 2012). The targeting construct was confirmed by sequencing, linearized, and subsequently electroporated into mouse sv129 ES cells. Correctly targeted ES cell clones were independently injected into C57BL/6 blastocysts and subsequently implanted into pseudopregnant females. Chimeric offspring were backcrossed to C57BL/6, and the $\mathrm{F}_{1}$ hybrid bred to FLP deleter mice for removal of the neomycin cassette. In tissues expressing Cre recombinase, the excision of exon 6 results in the same genetic lesion as the previously generated $C d k l 5$ constitutive knock-out line, causing a reading frame shift and a TAA stop codon in the $5^{\prime}$ end of exon 7 resulting in the truncation of CDKL5 at the $\mathrm{N}$-terminal kinase domain. The $C d k l 5$ floxed mouse line is available from The Jackson Laboratory (Stock no. 030523).

Animal husbandry. Experiments were conducted in accordance with the ethical guidelines of the National Institutes of Health and with the approval of the Institutional Animal Care and Use Committee of the University of Pennsylvania. The $C d k l 5^{\text {flox }}$ allele was generated on a congenic sv129:C57BL/6 background and backcrossed to C57BL/6 for at least 10 generations. Nex-Cre mice (Goebbels et al., 2006; RRID: MGI: 4429523), generously shared by Klaus-Armin Nave (Max Planck Institute of Experimental Medicine, Göttingen, Germany) and Lazzerini Denchi (The Scripps Research Institute), were obtained on a sv129 background and also backcrossed to C57BL/6 for at least 10 generations before breeding. Mice were genotyped using a PCR-based strategy to detect the presence of the $C d k l 5$ conditional knock-out allele containing a loxPflanked exon 6 . The genotyping primers (5'-CCACCCTCTCAGTAA GGCAGCAG-3' and 5'-GTCCTTTTGCCACTCAATTCCATCC-3') give rise to a $653 \mathrm{bp}$ product from the wild-type allele and $765 \mathrm{bp}$ product from the conditional knock-out allele with unexcised exon 6. For genotyping of Nex-Cre, primers and genotyping strategy were identical to that used by Goebbels et al. (2006).

Mice were group-housed in cages of three to five in a $12 \mathrm{~h} \mathrm{light/dark}$ cycle with food and water provided ad libitum. Each breeding cage consisted of two homozygous female mice (genotype: $C d k l 5^{\text {flox }} / C d k l 5^{\text {flox }}$ ) and one male mouse (genotype: Nex-Cre/+). Male littermates (genotypes: $C d k l 5^{\text {flox }} / \mathrm{y} ;+/+$ and $C d k l 5^{\text {flox }} / \mathrm{y}$;Nex-Cre) were weaned at 3 weeks of age and housed together, with all experiments performed on agematched adult mice between 9 and 12 weeks of age.

For spine imaging, homozygous female mice (genotype: $C d k l 5^{\text {flox }}$ / $C d k l 5^{\text {flox }}$ ) were bred to male mice carrying an allele expressing Thy1-GFP (line M; RRID: IMSR_JAX:007788). Male littermates (genotypes: $C d k 15^{\text {flox }} / \mathrm{y}$; +/+;Thyl-GFPm/+ and Cdkl5 ${ }^{\text {flox} / y ; N e x-C r e ; T h y l-G F P m /+) ~ w e r e ~ w e a n e d ~}$ at 3 weeks of age and housed together, with all experiments performed on age-matched adult mice between 9 and 12 weeks of age.

Western blot. Adult male mice (genotypes: $C d k l 5^{\text {flox }} / \mathrm{y} ;+/+$ and $C d k l 5^{\text {flox }} / \mathrm{y}$; Nex-Cre) were killed by cervical dislocation. After decapitation, brains were removed and sectioned into $1 \mathrm{~mm}$ coronal slices using a mouse brain matrix. Tissue was dissected from the somatosensory cortex, striatum, hippocampus, and cerebellum and homogenized in lysis buffer containing 1\% NP-40, pH 8.0. Protein concentration was measured using the Bradford assay and a total of $20 \mu \mathrm{g}$ protein was loaded for each lane.

Primary antibodies used in this study are anti-N-terminal CDKL5 (generated by Wang et al., 2012; diluted 1:500), anti-GAPDH (MA515738, Invitrogen; RRID: AB_10977387; diluted 1:1000), and anti- $\beta$ actin (AB8226, Abcam; RRID: AB_306371; diluted 1:1000). Secondary antibodies (LI-COR) are goat anti-rabbit IRDye 800CW (RRID: AB 10796098) and donkey anti-rabbit IRDye 680RD (RRID: AB_10954442) at dilutions of 1:10,000. Standard protocols were used for the Odyssey Infrared Imaging System (LI-COR) for visualization and quantification.

Behavioral assays. All animal behavioral studies were performed blinded to genotype. Mice were allowed to habituate to the testing room for at least $1 \mathrm{~h}$ before the test, and testing was performed at the same time of day. All animal behaviors were performed on adult male mice at 9-12 weeks of age, and the analysis of behavioral data were performed by a researcher blinded to genotype.

Elevated zero maze. The elevated zero maze (Stoelting) consists of a circular-shaped platform elevated above the floor. Two opposite quadrants of the maze are enclosed (wall height, 12 inches), whereas the other two are open (wall height, 0.5 inches). Mice were placed in one of the closed quadrants and their movement traced over the course of $5 \mathrm{~min}$. Analysis, including the quantification of percentage of time spent in open arms and the number of entries, was performed manually using a stopwatch. An entry was defined as a transition from a closed to open arm, or vice versa, that involves all four paws.

Three-chambered social approach assay. The social approach assay was performed as previously described (Sankoorikal et al., 2006; Fairless et al., 2013). The social choice test was performed in a three-chambered apparatus that consisted of a center chamber and two end chambers. 
Before the start of the test and in a counter-balanced sequence, one end chamber was designated the "social chamber", into which a stimulus mouse would be introduced, and the other end chamber was designed the "nonsocial chamber". Two identical clear, Plexiglas cylinders with multiple holes to allow for air exchange were placed in each end chamber. In the habituation phase of the test, the test mouse was placed in the center chamber and allowed to explore all three chambers for $10 \mathrm{~min}$. During this acclimation period, baseline measurements of how much time the mouse spent in each of the three chambers and the distance traveled by the test mouse were collected.

In the social choice phase of the test, a stimulus mouse (adult gonadectomized A/J mice; The Jackson Laboratory) was placed in the cylinder in the social chamber while a novel object was simultaneously placed into the other cylinder in the nonsocial chamber. During the $5 \mathrm{~min}$ social choice period, chamber times and numbers of transitions among chambers were again recorded.

In the direct social interaction test, the cylinders were removed simultaneously following the social choice test, and the amount of time test and stimulus mice spent in direct contact (sniffing, allogrooming) was measured. If fighting persisted for more than several seconds, the mice were removed from the apparatus and excluded from the study.

$Y$-maze. Spontaneous alternation behavior was measured on a Y-maze apparatus (San Diego Instruments), composed of three arms (Arm A: $8 \times 5 \times 3$ inches; Arms B and C: $6 \times 5 \times 3$ inches). For habituation, the test mouse was placed in each of the three arms, facing the center, and allowed to make one choice to enter another arm. For testing, the mouse was placed in Arm C, facing the center, and allowed to freely explore the maze for $5 \mathrm{~min}$. A spontaneous alternation was defined an entry into the arm less recently explored. Percentage spontaneous alternation was calculated as the number of spontaneous alternations over the total number of entries. For example, the sequence C, B, A, B, C, B, A, C (starting in $\operatorname{arm} C$ ) resulted in a percentage spontaneous alternation of $4 / 6=67 \%$.

Barnes maze. Hippocampal-dependent memory was assessed on a Barnes Maze apparatus (San Diego Instruments), a circular platform with a 36 inch diameter and 20 equally spaced escape holes along the perimeter, one of which leads to a "target" escape box. Bright lighting was used as stimulus to complete the task. The assay consisted of five phases: adaptation, forward acquisition training, forward probe trials, reversal training, and reversal probe trials. For adaptation, each mouse was placed in a dark start chamber in the middle of the maze for $10 \mathrm{~s}$, then uncovered and guided gently to the escape box. Forward acquisition training consisted of two trials per day for $4 \mathrm{~d}$, with each mouse starting in the dark start chamber in the middle of the maze and subsequently allowed to explore the maze for $3 \mathrm{~min}$. The trial ends when the mouse enters the target escape hole or after 3 min have elapsed, after which the mouse is guided gently to the escape hole. After reaching the escape hole, the mouse is allowed to remain there for $1 \mathrm{~min}$. Forward probe trials were conducted on Day 5, $24 \mathrm{~h}$ after the last training day. During the probe trial, the maze is in the same position as the training days, and the target hole is closed. Each trial lasted $90 \mathrm{~s}$, during which the number of errors (pokes into nontarget holes) made before reaching the target hole is quantified. Days 6 -10 consisted of reversal training, conducted using a similar protocol as forward acquisition training, except that the target was a stable escape hole moved $180^{\circ}$ from its location during forward acquisition training. Reversal probe trials were conducted on Day 11 and identically to forward probe trials. In addition to quantifying the number of total errors, the number of perseverations, defined as pokes into the previous target hole during forward acquisition training, was counted.

Locomotor assay. Locomotor activity was measured by beam breaks in a photobeam frame (Med Associates). Mice were individually placed into a clean home cage-like environment lined with bedding and resting within a photobeam frame. The number of beam breaks as a measure of locomotor activity was quantified over $30 \mathrm{~min}$ in $5 \mathrm{~min}$ bins.

Accelerating Rotarod assay. Mice were placed on an accelerating Rotarod apparatus (Med Associates) for 25 trials ( 5 trials a day on 5 consecutive days) with at least $15 \mathrm{~min}$ of rest between the trials. Each trial lasted for a maximum of $5 \mathrm{~min}$, during which the rod accelerated linearly from 3.5 to $35 \mathrm{rpm}$. The amount of time for each mouse to fall from the rod was recorded for each trial.
Olfaction. Mice were tested for whether they could detect and differentiate odors in a habituation-dishabituation protocol modified from Yang and Crawley (2009). Mice were presented with cotton-tipped wooden applicators dipped in water, vanilla, or swiped across the bottom of an unfamiliar social cage. Each stimulus was presented for 2 min with a $1 \mathrm{~min}$ intertrial interval. Time spent sniffing was defined as when the animal was oriented with its nose $2 \mathrm{~cm}$ or closer toward the cotton tip.

Repetitive behavior. Mice were individually placed into a clean home cage-like environment lined with bedding. After allowing $5 \mathrm{~min}$ for habituation, $10 \mathrm{~min}$ of activity was videotaped for each mouse. The duration of repetitive behavior, defined as grooming or digging, was scored manually using a stopwatch.

Nesting. Nesting behavior was scored as previously described (Deacon, 2006). Four- to 5-week old mice were assessed for amount of cotton material used after $20 \mathrm{~h}$ and for the height and shape of the nest.

Hindlimb clasping. Mice were suspended by the base of their tail at least 6 inches above a flat surface for up to $2 \mathrm{~min}$. If a period of sustained clasping (at least $2 \mathrm{~s}$ ) of the hindlimbs or all four limbs were observed, the mouse was scored as a positive for the hindlimb clasping phenotype.

Dendritic branching and dendritic spine analysis. All steps of sectioning, imaging, and data analysis were performed by a researcher blinded to genotype. Adult male mice 9 weeks of age (genotypes: $C d k l 5^{\text {flox }} / \mathrm{y} ;+/+$; Thyl-GFPm/+ and Cdkl5 flox/y;Nex-Cre;Thy1-GFPm/+) were transcardially perfused with $4 \%$ paraformaldehyde. Brains were extracted and postfixed additionally for $1 \mathrm{~h}$. For dendritic branching analysis, brains were embedded in $2 \%$ agar and sectioned coronally at $200 \mu \mathrm{m}$ on a Leica VT1000S vibratome. For dendritic spine analysis, brains were cryoprotected by sinking in 30\% sucrose in PBS, frozen in OCT (Sakura Finetek). Frozen brains were sectioned coronally at $50 \mu \mathrm{m}$ on a Leica CM3050S cryostat. For both dendrite and spine imaging, unstained sections were mounted with CFMR2 (Citifluor).

GFP-positive pyramidal neurons located in the hippocampal CA1 region (approximately between bregma coordinates -1.34 to -1.94 ) with well preserved morphology were chosen for imaging. For dendritic branching, confocal image stacks were taken on a laser scanning confocal microscope (Leica TCS SP8, 488 laser) with a $20 \times / 0.75$ NA immersion objective at $1 \times$ zoom. Each neuron was oriented diagonally and centered in a field of view with dimensions $553.57 \times 553.57 \mu \mathrm{m}$, with a step size of $0.5 \mu \mathrm{m}$. For dendritic spines, secondary and tertiary dendritic branches of basal and proximal apical dendrites, excluding the apical tuft, of CA1 pyramidal neurons were imaged. Image stacks were taken with a $63 \times 1$ 1.40 NA oil-immersion objective at $4 \times$ zoom. Each dendritic segment was centered in a field of view with dimensions $43.93 \times 10.95 \mu \mathrm{m}$, with a step size of $0.22 \mu \mathrm{m}$ and total depth spanning a depth of $<7 \mu \mathrm{m}$.

All image analysis was performed by a researcher blinded to genotype. For dendritic branching analysis, the dendrites of each neuron were traced in a supervised manner using Imaris FilamentTracer (Bitplane; RRID: SCR_007366). Each branch was individually traced using a combination of the Autopath and Autodepth functions, with the center of the soma designated as the dendrite beginning point. The basal and apical dendritic trees were separately traced. Sholl analysis was automatically performed by Imaris, and the statistics were exported for analysis.

For spine analysis, three-dimensional blind deconvolution was first performed on confocal image stacks with an iterative constrained Tikhonov-Miller algorithm (DeconvolutionLab, ImageJ) using a pointspread function generated from the imaging parameters (PSF Generator, ImageJ). The deconvolved image stack was imported into Imaris and analyzed. The dendritic backbone of each segment was first traced using the Autopath function and a cone-type dendrite diameter was built using a contrast threshold of 0.2 and dendrite maximum diameter of $1 \mu \mathrm{m}$. A sample spine was drawn from the dendritic backbone using the Autopath function. Subsequently, seed points for spine heads with a maximum distance of $3 \mu \mathrm{m}$ from the dendritic backbone, with the manual addition of seed points for any longer spines and curation of obvious false-positive and false-negative detections. Imaris performed automated computation of spine density and estimation of morphometric parameters for individual spines, including spine length, terminal diameter, and volume.

Ex vivo slice preparation. All steps of electrophysiological experiments, including data collection and analysis, were performed by a researcher 
blinded to genotype. Acute hippocampal slices were prepared from mice 9-12 weeks of age. Animals were anesthetized with isoflurane and transcardially perfused with ice-cold oxygenated $\left(95 \% \mathrm{O}_{2}, 5 \% \mathrm{CO}_{2}\right)$ cutting artificial CSF (aCSF) solution containing the following (in $\mathrm{mM}$ ): $2.5 \mathrm{KCl}$, $1.25 \mathrm{NaH}_{2} \mathrm{PO}_{4}, 5 \mathrm{MgSO}_{4}, 0.5 \mathrm{CaCl}_{2}, 200$ sucrose, $25 \mathrm{NaHCO}_{3}, 25$ glucose, $\sim 300 \mathrm{mOsm}, 7.2-7.4 \mathrm{pH}$. After decapitation, brains were removed for sectioning in the same ice-cold cutting aCSF using a Vibratome (Leica Microsystems 1200S). For whole-cell patch-clamp recordings of $\mathrm{mE} /$ IPSCs and the measurement of intrinsic membrane properties, $350 \mu \mathrm{m}$ transverse hippocampal sections were prepared. For all voltage-sensitive dye experiments, $400 \mu \mathrm{m}$ transverse hippocampal sections were prepared. Slices were recovered in the same cutting aCSF solution at $32^{\circ} \mathrm{C}$ for $30 \mathrm{~min}$ and transferred to an oxygenated room-temperature solution composed of $50 \%$ cutting aCSF and 50\% regular aCSF containing the following (in $\mathrm{mm}$ ): $125 \mathrm{NaCl}, 2.5 \mathrm{KCl}, 1.25 \mathrm{NaH}_{2} \mathrm{PO}_{4}, 10$ glucose, 26 $\mathrm{NaHCO}_{3}, 2 \mathrm{CaCl}_{2}, 1 \mathrm{MgCl}_{2}, \sim 300 \mathrm{mOsm}, 7.2-7.4 \mathrm{pH}$ for $30 \mathrm{~min}$. Subsequently, slices were transferred to $100 \%$ regular aCSF at room temperature for an additional $30 \mathrm{~min}$ before recording. All recordings were performed at $34^{\circ} \mathrm{C}$.

Intrinsic membrane properties. A pipette internal solution containing the following (in mM): $130 \mathrm{~K}$-gluconate, $6.3 \mathrm{KCl}, 1 \mathrm{MgCl}_{2}, 0.5 \mathrm{EGTA}$, 10 HEPES, 4 MgATP, $0.3 \mathrm{NaGTP}, 280-290 \mathrm{mOsm}$ was used. Input resistance was measured using $10 \mathrm{mV}$ test pulses, in the absence of any resistance compensation. An input-output curve was generated in current-clamp mode using $300 \mathrm{~ms}$ constant-current steps of increasing intensity $(0-120 \mu \mathrm{A}$ at $20 \mu \mathrm{A}$ intervals) and counting the number of action potentials during the time window. Spike threshold (action potential threshold) was determined in current-clamp mode using depolarizing current steps in $10 \mathrm{pA}$ increments until single action potentials were elicited, and the threshold voltage was determined as the membrane potential at the beginning of the sharp upward rise of the depolarizing phase of the action potential.

mEPSCs. A pipette internal solution containing the following (in $\mathrm{mm}$ ): $140 \mathrm{KCH}_{3} \mathrm{OSO}_{3}, 5 \mathrm{KCl}, 0.5$ EGTA, $1 \mathrm{MgCl}_{2}, 10$ HEPES, 5 MgATP, 0.25 NaGTP, $\sim 292 \mathrm{mOsm}, \mathrm{E}_{\mathrm{Cl}}=-78.8 \mathrm{mV}$ was used. Pipettes $4-6 \mathrm{M} \Omega$ in resistance were pulled from borosilicate glass capillaries (World Precision Instruments, 1B150F-4) on a Sutter Instruments P-1000 pipette puller. Voltage-clamp traces $5 \mathrm{~min}$ in duration were recorded at a holding potential of $-70 \mathrm{mV}$ in the presence of $1 \mu \mathrm{M}$ tetrodotoxin (Tocris Bioscience). All recordings were conducted with access resistance of $<20 \mathrm{M} \Omega$, leak current of $<100 \mathrm{pA}$, and an applied series resistance compensation of $80 \%$. Cells that did not maintain these parameters for the duration of the recording were eliminated. Analysis of miniature EPSCs (mEPSCs) was performed using pCLAMP10 (Molecular Devices) using a variable-amplitude template method, generated from a stable recording of at least $50 \mathrm{mEPSC}$ events. Each trace was first low-pass filtered at $1 \mathrm{kHz}$, and negative-going mEPSCs were detected using a template match threshold of 4 , without fitting.

mIPSCs. To record mIPSCs while maintaining a hyperpolarized membrane voltage, a high-chloride pipette internal solution containing the following (in mM): $100 \mathrm{CsCH}_{3} \mathrm{O}_{3} \mathrm{~S}, 50 \mathrm{CsCl}, 10 \mathrm{HEPES}, 0.2$ BAPTA, $3 \mathrm{KCl}, 1 \mathrm{MgCl}_{2}, 0.25$ GTP-Tris, 2.5 creatine phosphate disodium, 2 MgATP, $\sim 296 \mathrm{mOsm}, \mathrm{E}_{\mathrm{Cl}}=-23.7 \mathrm{mV}$ was used. Pipettes $4-6 \mathrm{M} \Omega$ in resistance were pulled from borosilicate glass capillaries (World Precision Instruments, 1B150F-4) on a Sutter Instruments P-1000 pipette puller. Voltage-clamp traces $3 \mathrm{~min}$ in duration were recorded at a holding potential of $-70 \mathrm{mV}$ in the presence of $1 \mu \mathrm{M}$ tetrodotoxin (Tocris Bioscience) and $2 \mathrm{~mm}$ kynurenic acid (Sigma-Aldrich). All recordings were conducted with access resistance of $<20 \mathrm{M} \Omega$, leak current of $<100$ $\mathrm{pA}$, and an applied series resistance compensation of $80 \%$. Cells that did not maintain these parameters for the duration of the recording were eliminated. Analysis of mIPSCs was performed using pCLAMP10 (Molecular Devices) using a variable-amplitude template method, generated from a stable recording of at least 50 mIPSC events. Each trace was first low-pass filtered at $1 \mathrm{kHz}$, and negative-going mIPSCs were detected using a template match threshold of 4 , without fitting.

Evoked AMPA/NMDA currents. A pipette internal solution containing the following (in mM): $125 \mathrm{CsCH}_{3} \mathrm{O}_{3} \mathrm{~S}, 4 \mathrm{NaCl}, 1$ EGTA, 10 HEPES, 4 MgATP, 0.3 NaGTP, 10 creatine phosphate disodium, 0.1 spermine tet- rahydrochloride was used. A concentric bipolar tungsten microelectrode was used for stimulation of the Schaffer collaterals. To normalize the stimulus intensity for evoked currents, the minimal stimulus to achieve a threshold evoked response was first determined. Subsequently, a stimulus twice the intensity of the minimal stimulus was used to elicit evoked currents. Voltage-clamp traces were recorded at a holding potential of $-70 \mathrm{mV}$ (for AMPA-EPSCs) or $+40 \mathrm{mV}$ (for NMDA-EPSCs) in the presence of $50 \mu \mathrm{m}$ picrotoxin (Tocris Bioscience). For each cell, at least 10 trials were averaged to obtain a representative response at each holding potential. The peak EPSC amplitude at $-70 \mathrm{mV}$ was taken as the magnitude of the AMPA-EPSCs. To estimate the NMDA-dependent contribution to the EPSC at $+40 \mathrm{mV}$, the EPSC amplitude at $75 \mathrm{~ms}$ poststimulus was used. Control experiments using the selective NMDA antagonist D-AP5 confirmed that at $75 \mathrm{~ms}$, the AMPA-dependent contribution to the EPSC at $+40 \mathrm{mV}$ is very small compared with the NMDA-dependent contribution. To calculate the NMDA/AMPA ratio, the magnitude of the NMDA-dependent component at $+40 \mathrm{mV}$ was divided by the peak amplitude of the AMPA-EPSC at $-70 \mathrm{mV}$.

Extracellular field recordings. Pipettes 2-4 $\mathrm{M} \Omega$ in resistance were pulled from borosilicate glass capillaries (World Precision Instruments, 1B150F-4) on a Sutter Instruments P-1000 pipette puller and filled with regular aCSF. Recordings were conducted in the stratum radiatum of CA1, 400-500 $\mu \mathrm{m}$ from the site of stimulation. For stimulation of the Schaffer collateral pathway, a concentric bipolar stimulation electrode (World Precision Instruments) was placed in stratum radiatum at the CA3-CA1 junction. The half-maximal stimulus intensity was determined for each slice by generating a standardized curve using stimuli of increasing intensity $(0-200 \mu \mathrm{A})$ and approximating the minimum intensity that elicited the half-maximal fEPSP amplitude. The peak amplitude of the presynaptic fiber volley preceding the field EPSP, measured from baseline, was used as an approximation of the number of fibers recruited by a given stimulus.

Paired-pulse ratios. Two successive stimuli with a $60 \mathrm{~ms}$ interval were applied at the approximate half-maximal stimulus intensity. An average trace from five trials was generated for each slice. The paired-pulse ratio was calculated as the amplitude of the second EPSP divided by the amplitude of the first EPSP.

Voltage-sensitive dye imaging. Following recovery, each slice was bulkloaded with $100 \mu \mathrm{l}$ of a solution containing the voltage-sensitive dye di-2-ANEPEQ (Antić and Zecević, 1995; Habib-E-Rasul Mullah et al., 2013; JPW1114, Invitrogen) diluted at $0.05 \mathrm{mg} / \mathrm{ml}$ in aCSF. Each slice was stained for $14 \mathrm{~min}$, washed with aCSF, and imaged in an interface chamber using an $80 \times 80 \mathrm{CCD}$ camera recording with a $1 \mathrm{kHz}$ frame rate (NeuroCCD; RedShirt Imaging). Illumination was provided by a $530 \mathrm{~nm}$ Green LED (Thor Labs, M530L3-C2). A filter set (Chroma Technologies $11007 v 2$ wide Green) was used to allow excitation at 510-560 $\mathrm{nm}$ and collection of emitted fluorescence at a wavelength $>592 \mathrm{~nm}$. Trials lasted $1000 \mathrm{~ms}$ each, with a $20 \mathrm{~s}$ intertrial interval. Interleaved trials without stimulation allowed for background subtraction.

All data analysis was performed in IGOR (Wavemetrics) on the average of 12 trials. Data were displayed as the change in fluorescence divided by the resting fluorescence $(\Delta F / F)$. Regions-of-interest (ROIs) were drawn proximal $(0-270 \mu \mathrm{m})$ and distal $(270-540 \mu \mathrm{m})$ to the site of stimulation, with the following approximate dimensions (in pixels): $30 \times 30$ for stratum radiatum and $15 \times 30$ for stratum pyramidale/ oriens. Like other dyes of the ANEPP family, di-2-ANEPEQ decreases in fluorescence upon membrane depolarization. To be consistent with electrophysiological conventions, depolarizing $\Delta F / F$ signals were displayed as upward signals (warmer colors) and hyperpolarization $\Delta F / F$ signals were displayed as downward signals (colder colors). Snapshots of VSDI represent a $70 \times 70$ pixel trimmed window, corresponding to an $\sim 635 \times$ $635 \mu \mathrm{m}$ field of view.

Statistical analyses. On the basis of previously published CDKL5 mouse models, we chose similar sample sizes for all behavioral experiments performed. For assays other than behavior, we determined approximate sample size and power from effect sizes found in related models of neurodevelopmental disorders. Importantly, the number of mice used for each experiment was predetermined before the start of the experiment. 
Table 1. Linear mixed-model analysis of datasets involving subsampling

\begin{tabular}{|c|c|c|c|c|c|}
\hline \multirow[b]{2}{*}{ Assay } & \multicolumn{5}{|l|}{ LME with Kenward-Roger approximation } \\
\hline & Estimated effect of genotype (Nex-cK0- WT) & Fstatistic & $\mathrm{df}$, numerator & $\mathrm{df}$, denominator & $p$ value \\
\hline Basal spine density & 2.299 spines $/ 10 \mu \mathrm{m}$ & 4.25 & 1 & 3.86 & 0.111 \\
\hline Apical spine density & 2.204 spines $/ 10 \mu \mathrm{m}$ & 8.22 & 1 & 3.50 & 0.054 \\
\hline Basal spine volume & $0.02344 \mu \mathrm{m}^{3}$ & 5.88 & 1 & 3.63 & 0.079 \\
\hline Apical spine volume & $0.01653 \mu \mathrm{m}^{3}$ & 2.46 & 1 & 3.74 & 0.197 \\
\hline Basal dendrite (total length) & $-458.9 \mu \mathrm{m}$ & 4.86 & 1 & 4.42 & 0.086 \\
\hline Apical dendrite (total length) & $-150 \mu \mathrm{m}$ & 0.62 & 1 & 4.25 & 0.473 \\
\hline Basal dendrite (Sholl analysis) & No overall estimate ${ }^{a}$ & 3.27 & 19 & 875.03 & $3.12 \times 10^{-6}$ \\
\hline Apical dendrite (Sholl analysis) & No overall estimate ${ }^{a}$ & 2.26 & 23 & 1051.14 & 0.001 \\
\hline Spike threshold & $0.8803 \mathrm{mV}$ & 0.40 & 1 & 5.87 & 0.551 \\
\hline Input resistance & $22.31 \mathrm{M} \Omega$ & 0.73 & 1 & 5.97 & 0.427 \\
\hline Input- output curve & No overall estimate ${ }^{a}$ & 0.75 & 6 & 204.02 & 0.611 \\
\hline mEPSC frequency & $0.5851 \mathrm{~Hz}$ & 9.57 & 1 & 3.08 & 0.052 \\
\hline mEPSC inter-event intervals (binned) & No overall estimate ${ }^{a}$ & 5.28 & 19 & 696.00 & $4.63 \times 10^{-12}$ \\
\hline mEPSC median amplitude & $-2.928 \mathrm{pA}$ & 0.28 & 1 & 3.93 & 0.623 \\
\hline mEPSC amplitude (binned) & No overall estimate ${ }^{a}$ & 0.30 & 19 & 696.00 & 0.998 \\
\hline $\mathrm{mEPSC}$ rise time & $-0.1252 \mathrm{~ms}$ & 0.76 & 1 & 3.73 & 0.437 \\
\hline mEPSC decay time & $-0.1559 \mathrm{~ms}$ & 0.47 & 1 & 3.76 & 0.534 \\
\hline mEPSC charge transfer rate & $60.37 \mathrm{pA} \cdot \mathrm{ms} / \mathrm{s}$ & 2.39 & 1 & 3.68 & 0.203 \\
\hline AMPA-EPSC amplitude & $15.99 \mathrm{pA}$ & 0.27 & 1 & 5.16 & 0.625 \\
\hline NMDA-EPSC amplitude & $7.003 \mathrm{pA}$ & 0.54 & 1 & 4.65 & 0.498 \\
\hline NMDA/AMPA ratio & -0.01768 & 0.06 & 1 & 3.44 & 0.821 \\
\hline mIPSC frequency & $0.7923 \mathrm{~Hz}$ & 7.83 & 1 & 3.50 & 0.057 \\
\hline mIPSC inter-event intervals (binned) & No overall estimate ${ }^{a}$ & 2.32 & 19 & 656.00 & 0.001 \\
\hline mIPSC median amplitude & $-0.2231 \mathrm{pA}$ & 0.01 & 1 & 3.50 & 0.920 \\
\hline mIPSC amplitude (binned) & No overall estimate ${ }^{a}$ & 0.66 & 19 & 656.00 & 0.861 \\
\hline mIPSC rise time & $-0.09863 \mathrm{~ms}$ & 1.20 & 1 & 3.50 & 0.343 \\
\hline mIPSC decay time & $1.356 \mathrm{~ms}$ & 17.20 & 1 & 3.74 & 0.016 \\
\hline mIPSC charge transfer rate & $213.0 \mathrm{pA} \cdot \mathrm{ms} / \mathrm{s}$ & 12.86 & 1 & 3.50 & 0.029 \\
\hline Half-maximal stimulus & $-4.05 \mu \mathrm{A}$ & 1.10 & 1 & 6.27 & 0.332 \\
\hline Fiber volley amplitude & $0.04215 \mathrm{mV}$ & 0.27 & 1 & 8.06 & 0.619 \\
\hline Paired-pulse ratio & 0.003923 & 0.002 & 1 & 7.91 & 0.966 \\
\hline VSDI: proximal SR & No overall estimate ${ }^{a}$ & 3.97 & 5 & 201.55 & 0.002 \\
\hline VSDI: proximal SP/SO & No overall estimate ${ }^{a}$ & 7.61 & 5 & 201.30 & $1.42 \times 10^{-6}$ \\
\hline VSDI: distal SR & No overall estimate ${ }^{a}$ & 0.34 & 5 & 201.63 & 0.886 \\
\hline VSDI: distal SP/SO & No overall estimate ${ }^{a}$ & 2.25 & 5 & 201.20 & 0.051 \\
\hline
\end{tabular}

${ }^{a}$ For assays involving a third term (distance, cumulative frequency bin, or time), the statistics reported represent the interaction between genotype and the third term. No overall estimate of the fixed effect of genotype is reported because this parameter varies based on the third term.

For behavioral assays, statistical analyses were performed using Prism (GraphPad). All datasets were analyzed using the D'Agostino-Pearson omnibus test for normality. Datasets with normal distributions were analyzed for significance using unpaired Student's two-tailed $t$ test. Datasets with non-normal distribution were analyzed using the MannWhitney test. Two-way repeated-measures ANOVA was conducted for the appropriate datasets with Holm-Sidak's multiple-comparison test, using adjusted ${ }^{\star} p<0.05$.

All other assays that involved subsampling of animals were analyzed using R (The R Project for Statistical Computing). Each dataset was analyzed using a linear mixed-effect model, where "genotype" was modeled as a fixed effect term and "animal" was modeled as a random effect term. This model accounts for both between-animal and between-cell variation. For each assay, null and alternative models were constructed using the lmer function in the lme4 package (Bates et al., 2015) in the following format:

$$
\begin{aligned}
& \mathrm{m} 0=1 \mathrm{mer}(\text { Outcome } \sim(1 \mid \text { Animal }), \mathrm{REML}=\mathrm{TRUE}) \\
& \mathrm{m} 1=1 \mathrm{mer}(\text { Outcome } \sim \text { Genotype }+(1 \mid \text { Animal }),
\end{aligned}
$$$$
\text { REML }=\text { TRUE) } .
$$

For datasets involving a third term (e.g., time), the following null and alternative models were constructed, to test the significance of an interaction between Genotype and the third term:

$\mathrm{m} 0=1 \mathrm{mer}($ Outcome $\sim$ Time + Genotype $+(1 \mid$ Animal $)$,

REML $=$ TRUE) $\mathrm{m} 1=1 \mathrm{mer}($ Outcome $\sim$ Time $*$ Genotype $+(1 \mid$ Animal $)$,

$$
\text { REML }=\text { TRUE). }
$$

To make statistical comparisons, the KRmodcomp function from the pbkrtest package (Halekoh and Højsgaard, 2014) was used:

$$
\operatorname{KRmodcomp}(\mathrm{m} 0, \mathrm{~m} 1) \text {. }
$$

The KRmodcomp function reports a modified $F$ test statistic based on the Kenward and Roger approximation (Kenward and Roger, 1997), which accounts for the small sample sizes in our study, modified numerator and denominator degrees of freedom, and a $p$ value. The estimated effect of Genotype is obtained from the alternative model constructed using the lmer function from lme4.

For post hoc comparisons of VSDI time point data, we used the glht function from the multcomp package (Hothorn et al., 2008), with the $p$ values adjusted for multiple comparisons using Holm's method:

$\operatorname{summary}(\operatorname{glht}(\mathrm{m} 1, \operatorname{linfct}=\mathrm{K} \% * \% \mathrm{X})$,

$$
\text { test }=\operatorname{adjusted}(\text { type }=\text { "holm") }),
$$

where the argument for linfct is a matrix of coefficients representing the linear hypotheses to be tested. For voltage-sensitive dye imaging data, a total of six between-genotype comparisons were made, corresponding to six preselected time points poststimulus (0/8/10/20/40/60 ms). Results of linear mixed effect model analysis are reported in Tables 1 and 2.

For the analysis of cumulative distributions (mEPSC and mIPSC inter-event intervals and amplitudes), all samples from each individual 
Table 2. General linear hypothesis tests for VSDI at specific time points

\begin{tabular}{llll}
\hline & \multicolumn{2}{l}{$\begin{array}{l}\text { Generalized linear hypothesis tests with Holm's method } \\
\text { to adjust for multiple comparisons }\end{array}$} \\
\cline { 2 - 4 } & $\begin{array}{l}\text { Estimated effect of Genotype } \\
\text { (Nex-cKO-WT) }\end{array}$ & z value & $\begin{array}{l}\text { Adjusted } \\
p \text { value }\end{array}$ \\
\hline Assay & & & \\
\hline VSDI: proximal SR & $-6.803 \times 10^{-4} \Delta F / F$ & 3.789 & $9.06 \times 10^{-4}$ \\
$8 \mathrm{~ms}$ & $-5.403 \times 10^{-4} \Delta F / F$ & 3.01 & 0.013074 \\
$10 \mathrm{~ms}$ & & & \\
VSDI: proximal SP/SO & $-2.664 \times 10^{-4} \Delta F / F$ & 3.281 & 0.00621 \\
$8 \mathrm{~ms}$ & $-2.163 \times 10^{-4} \Delta F / F$ & 2.663 & 0.0387 \\
$10 \mathrm{~ms}$ & $1.930 \times 10^{-4} \Delta F / F$ & -2.377 & 0.06983 \\
$40 \mathrm{~ms}$ & & & \\
VSDI: distal SP/SO & $2.286 \times 10^{-4} \Delta F / F$ & -3.095 & 0.0118 \\
$20 \mathrm{~ms}$ & \multicolumn{3}{l}{} \\
\hline
\end{tabular}

cell was sorted, binned, and averaged at percentage intervals, effectively generating a binned cumulative distribution curve for each cell. Data from all cells of a given genotype were plotted at these distinct binned percentage intervals with the mean and error bars indicating SEM. The results were analyzed using linear mixed-effect models, incorporating a third term, "cumulative frequency bin". In two experiments (mEPSCs, AMPA/NMDA-EPSCs), Grubbs' test for outliers was applied with a threshold of $p<0.01$ on both wild-type and mutant datasets, with the excluded value noted in the figure legends.

All graphs are plotted using Prism (GraphPad). In our figures, $p$ values between 0.05 and 0.1 are shown explicitly, and the symbol ${ }^{*}$ is used to denote all $p$ values $<0.05$.

\section{Results}

\section{Nex-cKO mice exhibit impaired hippocampal-dependent} learning and memory

Cdkl5 constitutive knock-out mice exhibit a broad range of behavioral phenotypes, including impaired learning and memory, decreased social behavior, increased repetitive behavior, decreased anxiety, and impaired motor coordination (Wang et al., 2012). CDKL5 protein expression is highest in the forebrain (Wang et al., 2012), where glutamatergic and GABAergic neurons predominate. To isolate the cellular origins of CDKL5 deficiency-related phenotypes, we generated a mouse line selectively lacking CDKL5 in forebrain excitatory neurons (Nex-cKO), using the Nex-Cre mouse line (Goebbels et al., 2006; Fig. 1A). We then confirmed the cell-type-specific loss of CDKL5 in excitatory neuron-rich regions of the forebrain using Western blot analysis of microdissected tissues (Fig. 1B). In whole hippocampal lysates of Nex-cKO mice, CDKL5 protein levels were reduced by $\sim 85 \%$ (WT, 0.445, Nex-cKO, 0.068; Mann-Whitney test, $U=0, p=$ 0.029 ; Fig. $1 C$ ). We first performed a battery of behavioral tests to assess basic sensory and motor functions, including home-cage locomotion, anxiety, rotarod, olfaction, repetitive behavior, and nesting, and found that these behaviors were unaltered in NexcKO mice compared with wild-type littermates (Fig. $2 A-F$ ). Interestingly, we noted the emergence of a robust hindlimb clasping phenotype in Nex-cKO starting at $\sim$ postnatal day (P)80 that became fully penetrant by $\sim$ P120 (Fig. $2 G$ ).

We next assessed sociability and learning and memory, two aspects of behavior impaired in constitutive Cdkl5 knock-out mice that mirror the symptomatology of human CDKL5 deficiency (Wang et al., 2012). Compared with wild-type littermates, adult Nex-cKO mice demonstrated similar social behavior in the three-chamber social approach test, showing a strong preference for investigating a novel mouse over a novel object (Fig. $3 A, B$ ), as well as similar levels of direct social interaction with a novel mouse (WT: $64.1 \pm 7.3$; Nex-cKO: $53.4 \pm 3.9$; Mann-Whitney test, $p=0.55$; Fig. $3 C$ ). In contrast, on the Y-maze test, Nex-cKO

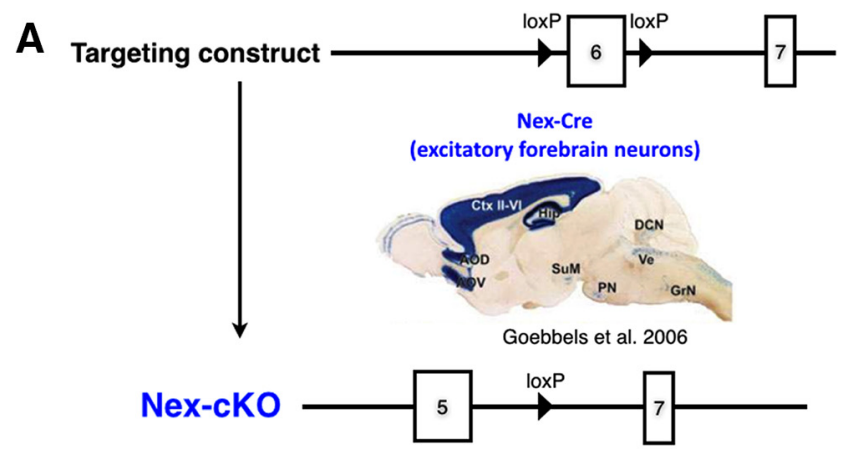

B

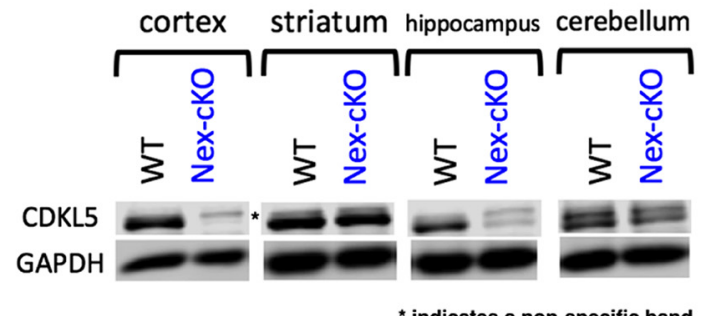

C

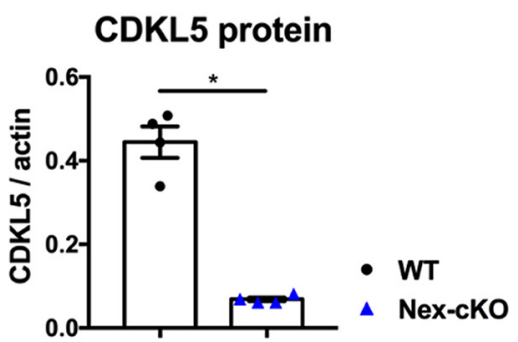

Figure 1. Generation of Nex-cKO mice and validation of conditional knock-out strategy. $\boldsymbol{A}$, Schematic of targeting construct, expression pattern of Nex-Cre (Goebbels et al., 2006), and the Cre-dependent excision of exon 6 of a floxed Cdkl5 allele. Nex-CKO (Nex-Cre; $\left.(d k / 5)^{f l o x} / y\right)$ male mice have a selective deletion of CDKL5 in forebrain glutamatergic neurons. $\boldsymbol{B}$, Because of the lack of a suitable antibody for CDKL5 immunohistochemistry, Western blotting was used to validate the cell-type-specificity of knock-out. In the cortex and hippocampus, brain regions enriched in glutamatergic neurons, CDKL5 levels are significantly reduced. In the striatum and cerebellum, where Nex-Cre expression is low, CDKL5 levels are not grossly altered. GAPDH was used as loading control in this panel. C, CDKL5 protein levels are reduced by $\sim 85 \%$ in whole hippocampal lysates of Nex-cKO mice. $\beta$-Actin was used as loading control in this panel. MannWhitney test, $n=4$ mice for WT, $n=4$ mice for Nex-cKO. Data are mean \pm SEM. ${ }^{*} p<0.05$.

mice exhibited significantly decreased spontaneous alternation (WT: $65.9 \pm 2.2 \%$; Nex-cKO: $53.9 \pm 2.3 \%$; unpaired $t$ test, $t_{(41)}=$ $3.737, p=0.0006$; Fig. $4 A$ ), suggestive of an impairment in spatial working memory. On the Barnes maze assay, Nex-cKO mice made more errors on both forward (WT: $44.3 \pm 5.0$ errors; NexcKO: $71.8 \pm 5.8$ errors; unpaired $t$ test, $\left.t_{(26)}=2.991, p=0.006\right)$ and reversal (WT: $52.1 \pm 5.7$ errors; Nex-cKO: $71.8 \pm 5.8$ errors; Mann-Whitney test, $U=19, p=0.0005)$ probe trials, and showed increased number of perseverations (WT: $2.4 \pm 0.4$ errors; Nex-cKO: $5.1 \pm 0.4$ errors; unpaired $t$ test, $t_{(26)}=3.896, p=$ $0.0006)$ to the original target during the reversal probe trial, suggesting a deficit in hippocampal-dependent memory (Fig. 4C-E). Interestingly, Nex-cKO mice also showed modestly increased locomotor activity in specific contexts outside of the home cage, as shown by higher activity during the social choice phase of the social approach assay (WT: $23.4 \pm 1.0 \mathrm{~m}$; Nex-cKO: $27.3 \pm$ $0.8 \mathrm{~m}$; Mann-Whitney test, $U=311, p=0.0015)$ and increased total number of entries on the Y-maze assay (WT: $29.3 \pm 1.3$ entries; Nex-cKO: $40.2 \pm 2.8$ entries; unpaired $t$ test, $t_{(41)}=$ 
A

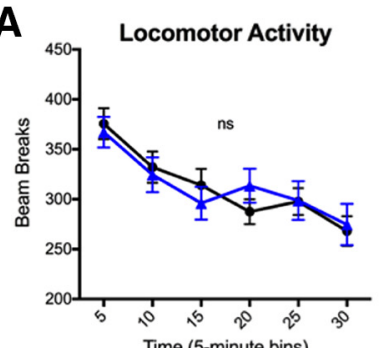

D

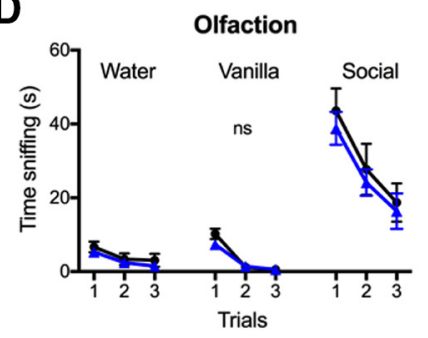

B

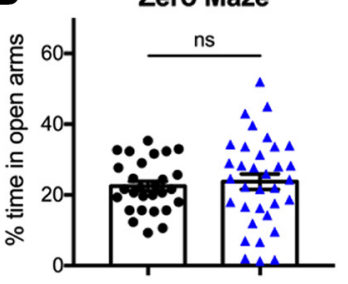

E Repetitive Behavior

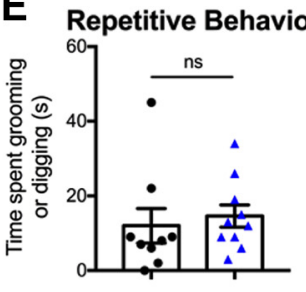

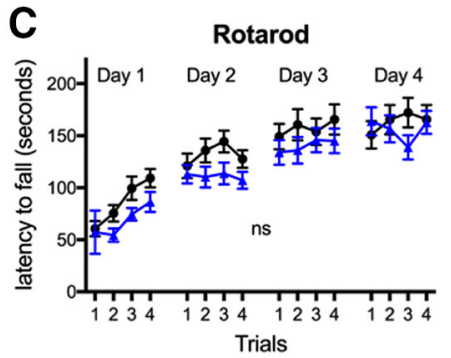

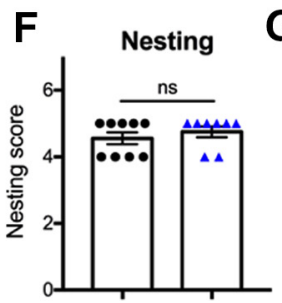

G

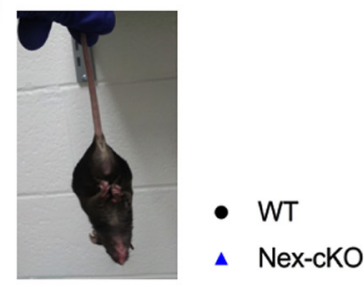

Figure 2. Assessment of home-cage locomotion, anxiety, motor coordination, olfaction, repetitive behavior, nesting, and hindlimb clasping in Nex-cK0 mice. $A$, Nex-cK0 mice exhibit unaltered locomotor activity during a 30 min exploration of a home cage-like environment (two-way repeated-measure ANOVA, $n=13$ mice for WT, $n=25$ mice for Nex-cKO). $\boldsymbol{B}$, In the elevated zero maze, Nex-cKO and WT mice spend similar times in open arms, demonstrating unaltered anxiety (unpaired $t$ test, $n=28$ mice for WT, $n=34$ mice for Nex-cKO). C, In the Rotarod assay, Nex-cK0 and WT mice exhibit similar latencies to fall and improvement over multiple trials, demonstrating unaltered motor coordination and learning. (two-way repeated-measure ANOVA, $n=27$ mice for WT, $n=$ 30 mice for Nex-CKO). D, In the olfactory habituation-dishabituation test, Nex-cKO and WT mice spend similar times sniffing various odors, demonstrating an intact preference for social over nonsocial scents. Nex-CKO and WT mice also demonstrate similar levels of habituation after repeated exposures to the same scent (two-way repeated-measure ANOVA, $n=9$ mice for WT, $n=14$ mice for Nex-cKO). E, Nex-cKO and WT mice exhibit similar levels of repetitive behavior (grooming or digging) in a home cage-like environment. (Mann-Whitney test, $n=9$ mice for WT, $n=10$ mice for Nex-cKO). $\boldsymbol{F}$, Nex-cK0 and WT mice achieve similar scores in the nest building assay. (Mann-Whitney test, $n=9$ mice for WT, $n=8$ mice for Nex-cK0). G, Image of a P120 Nex-cK0 mouse suspended by the tail, exhibiting limb clasping. WT mice consistently splay their hindlimbs outward in anticipation of landing. In contrast, Nex-cKO mice exhibit clasping of the hindlimbs and sometimes also fore limbs. In a cohort of P120 mice, 0/11 of WT mice and 17/18 (94\%) of Nex-cK0 mice exhibited limb clasping. The phenotype of limb clasping begins to emerge in Nex-cK0 mice at $\sim P 90$. Data are mean \pm SEM.

A
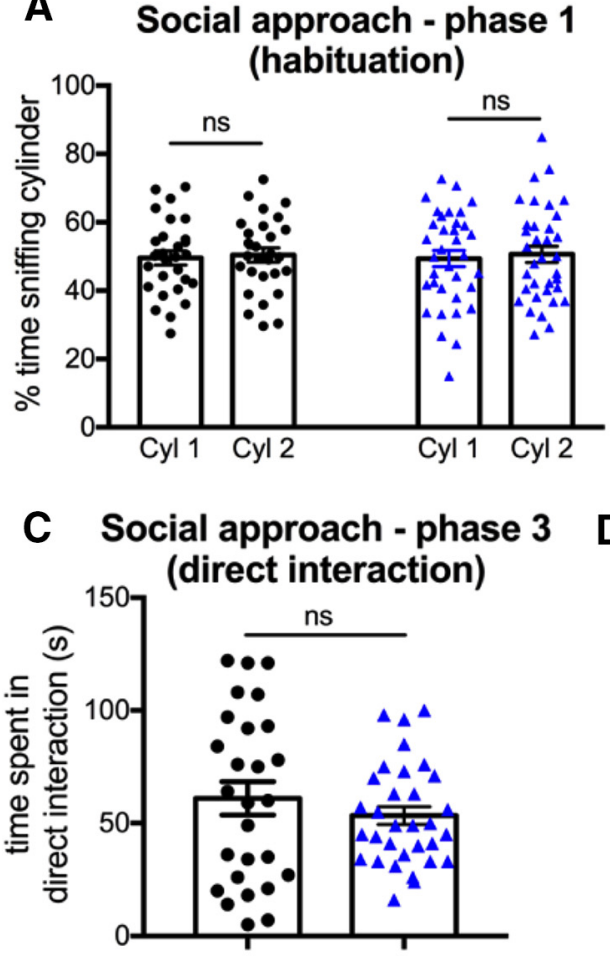

B Social approach - phase 2 (social choice)
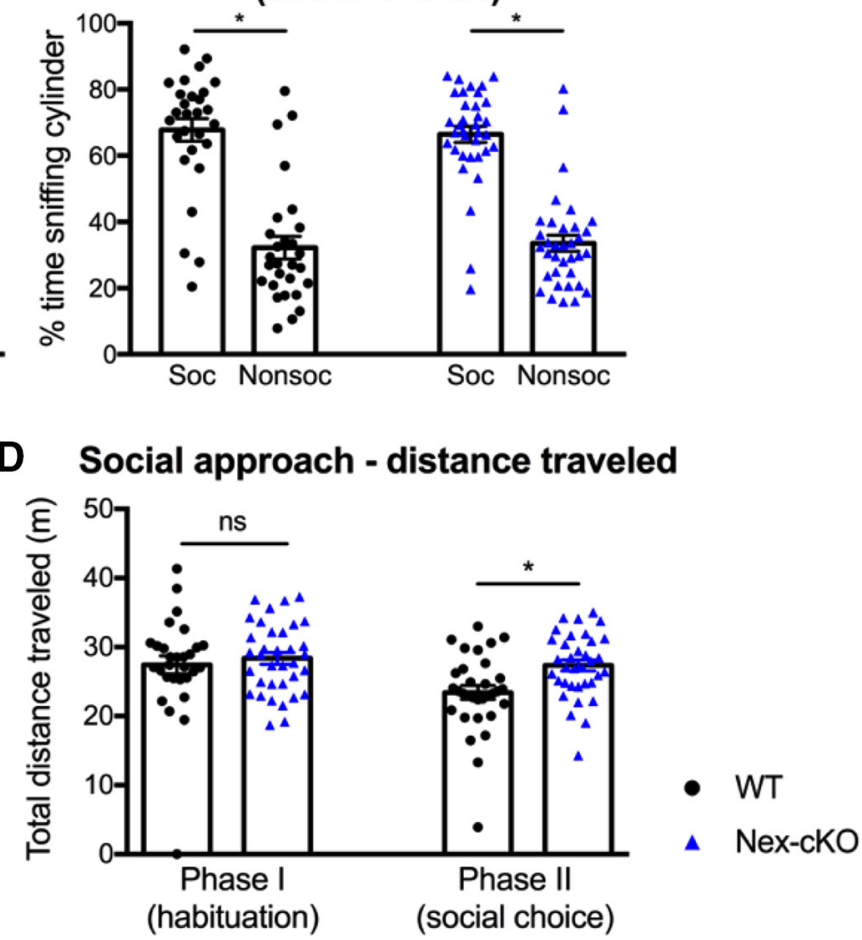

Figure 3. Unaltered sociability in Nex-cKO mice. $A$, WT and Nex-cKO mice did not exhibit a preference for either chamber during habituation (phase I) of the three-chambered social approach assay, when no stimulus mouse was present. $\boldsymbol{B}$, Similar to WT, Nex-cK0 exhibited a strong preference for the social chamber during social choice (phase II) of the three-chambered social approach test. C, Compared with WT, Nex-cKO mice exhibited similar levels of direct interaction with the stimulus mouse. D, WT and Nex-CKO mice exhibit similar levels of activity during habituation, but Nex-cKO mice become hyperactive during the social choice phase. Mann-Whitney test for all experiments. WT, $n=28$ mice; Nex-cK0, $n=35$ mice. Data are mean \pm SEM. ${ }^{*} p<0.05$. 

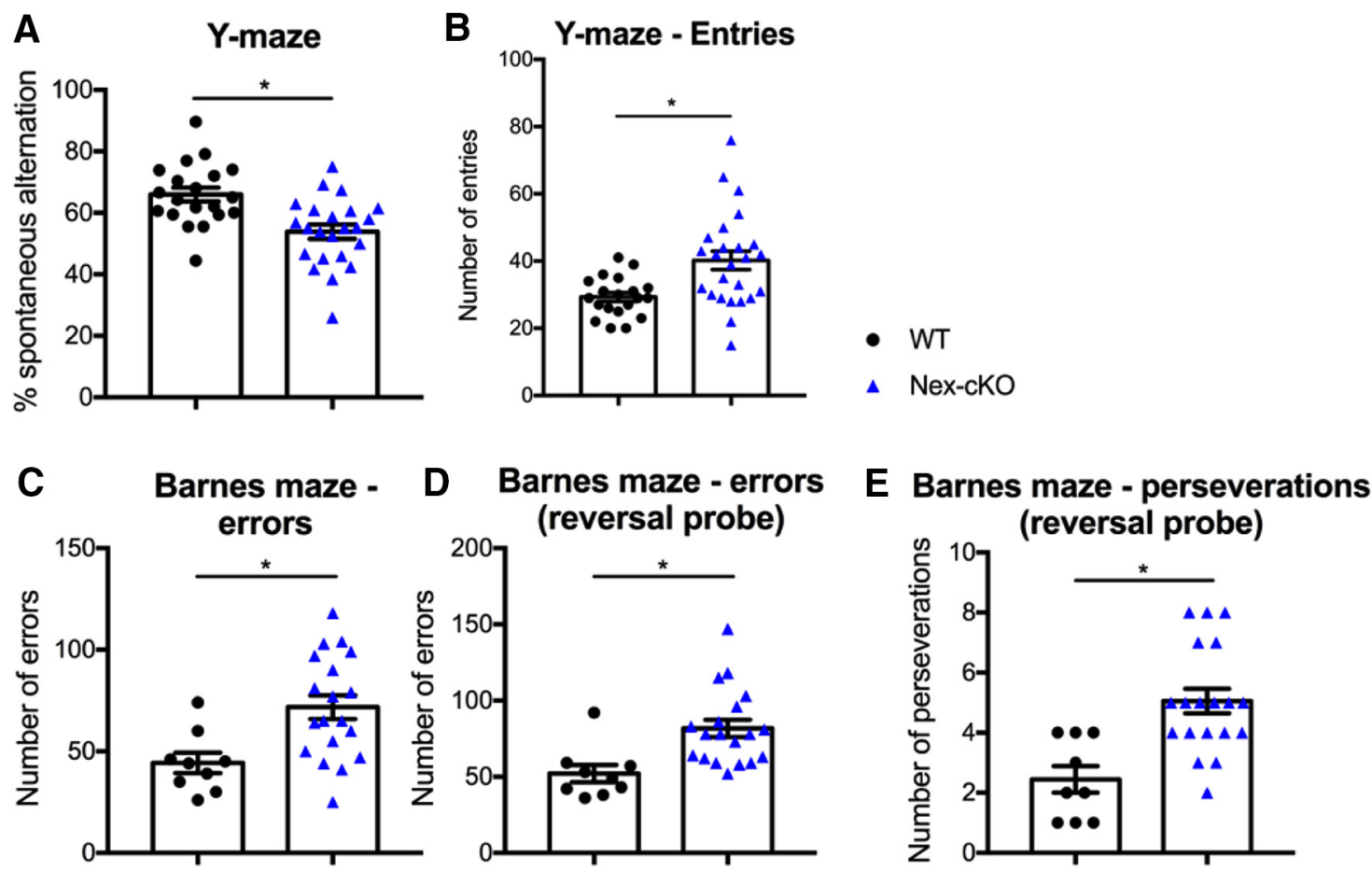

Figure 4. Impaired hippocampal-dependent learning and memory in Nex-cKO mice. $A$, Compared with wild-type (WT) littermates, Nex-cK0 mice showed decreased spontaneous alternation on the Y-maze assay (unpaired $t$ test, $n=20$ mice for WT and $n=23$ mice for Nex-cKO). $\boldsymbol{B}$, During the Y-maze assay, Nex-cK0 mice make a greater number of total entries into arms (unpaired $t$ test). $\boldsymbol{C}, \boldsymbol{D}$, During both the forward $(\boldsymbol{C})$ and reversal $(\boldsymbol{D})$ probe trials of the Barnes maze assay, Nex-cK0 mice made more errors before reaching the target hole (forward probe: unpaired $t$ test; reversal probe: Mann-Whitney test; $n=9$ mice for WT and $n=19$ mice for Nex-(KO). $\boldsymbol{E}$, During the reversal probe trials of the Barnes maze assay, Nex-cK0 mice also made more incorrect visits (perseverations) to the previous escape hole (unpaired $t$ test). Data are mean \pm SEM. ${ }^{*} p<0.05$.

3.294, $p=0.002$; Figs. 3D, 4B). Together, of the numerous phenotypes exhibited by Cdkl5 constitutive knock-out mice, NexcKO mice appear to recapitulate a relatively isolated impairment in hippocampal-dependent learning and memory upon the loss of CDKL5 from forebrain excitatory neurons.

\section{Altered morphology of CA1 pyramidal neurons of Nex-cKO mice}

CDKL5 has been found to interact with proteins that modulate the actin cytoskeleton (Chen et al., 2010) as well as the postsynaptic density (Ricciardi et al., 2012). However, the impact of CDKL5 loss on pyramidal neuron morphology has been highly context-dependent, varying across in vitro knockdown studies and in vivo studies in Cdkl5 constitutive knock-out mice (Chen et al., 2010; Ricciardi et al., 2012; Zhu et al., 2013; Sala et al., 2016). The Nex-cKO mouse line presented us with a unique opportunity to examine the excitatory neuron-autonomous consequences of CDKL5 loss on cellular morphology. We chose to focus our morphologic studies on CA1 pyramidal neurons, due to (1) previous findings suggesting that CDKL5 expression is highly enriched in the CA1 region (Lein et al., 2007; Cembrowski et al., 2016) and (2) the relatively specific impairment in hippocampaldependent learning and memory phenotype in Nex-cKO mice. By crossing Nex-cKO mice with a Thyl-GFPm allele (Feng et al., 2000), we were able to analyze dendritic complexity and dendritic spine density in vivo. Compared with wild-type littermates, adult Nex-cKO mice showed a significant decrease in the complexity of the basal and proximal apical dendrites of CA1 neurons, as shown by Sholl analysis (linear mixed-effect model analysis, interaction of genotype and distance from soma; basal dendrites: $F_{(19,875)}=$ 3.27, $p=3.12 \times 10^{-6}$; apical dendrites: $F_{(23,1051)}=2.26, p=$ 0.001 ; Fig. $5 A-E)$, confirming the results of a previous RNAi- mediated CDKL5 knockdown study (Chen et al., 2010) and constitutive knock-out study (Amendola et al., 2014). In Nex-cKO mice, total basal dendrite length also showed a trend toward a reduction [linear mixed-effect model analysis, fixed effect of genotype (Nex-cKO-WT): $-458.9 \mu \mathrm{m}, F_{(1,4.42)}=4.86, p=0.086$; Fig. $5 D$ ]. Next, we compared spine density in CA1 pyramidal neurons of wild-type and Nex-cKO mice. In Nex-cKO mice, we found, surprisingly, trends toward an increase in spine density, particularly in the apical dendrites of CA1 pyramidal neurons [linear mixed-effect model analysis, fixed effect of genotype (Nex-cKO-WT): 2.204 spines $/ 10 \mu \mathrm{m}, F_{(1,3.5)}=8.22$, $p=0.054$; Fig. $6 B, E]$. Reconstruction and analysis of spine morphology in three-dimensional confocal image stacks also revealed a trend toward an increase in spine volume in NexcKO mice [basal dendritic spines: linear mixed-effect model analysis, fixed effect of genotype (Nex-cKO-WT): 0.0234 $\mu \mathrm{m}^{3}, F_{(1,3.63)}=5.88, p=0.079$; Fig. $\left.6 C, F\right]$. Given that spine volume is positively correlated with spine maturity and the strength of the excitatory synapse it contains (Harris and Stevens, 1989; Nimchinsky et al., 2002; Arellano et al., 2007), our findings suggest that CA1 pyramidal neurons in Nex-cKO mice tend to have slightly increased density of morphologically mature dendritic spines.

\section{Enhanced excitatory synaptic activity in CA1 pyramidal} neurons of Nex-cKO mice

Because decreased dendritic branching and increased spine volume and density are not typically observed in concert, we next asked how this morphology affected function, particularly related to the intrinsic and synaptic properties of CA1 pyramidal neurons. Using the whole-cell patch-clamp technique in ex vivo hippocampal slices, we first investigated the intrinsic membrane 

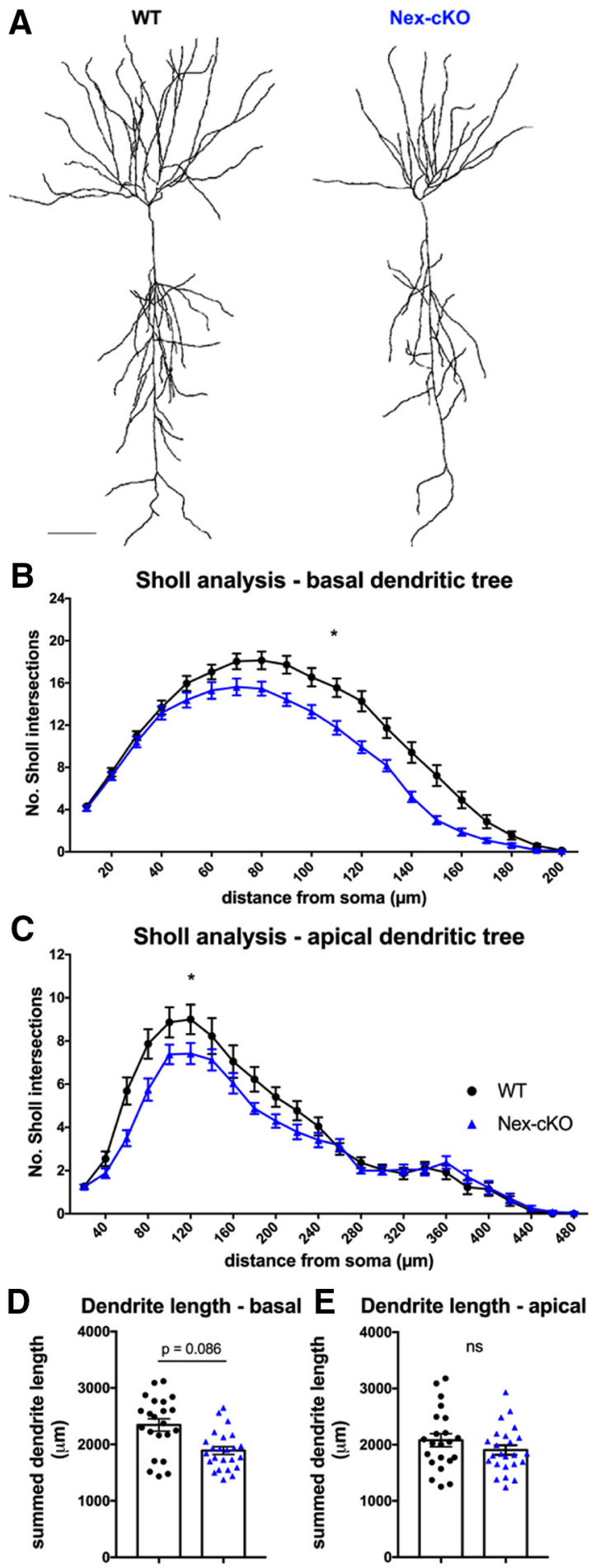

Figure 5. Decreased dendritic complexity in CA1 pyramidal neurons of Nex-cKO mice. $A$, Representative tracings of neurons from WT and Nex-cKO mice. Scale bar, $50 \mu \mathrm{m}$. B, Decreased branching of the basal dendritic tree in Nex-cKO mice. C, Decreased branching of proximal apical dendrites in Nex-cKO mice. $\boldsymbol{B}$, $\boldsymbol{C}$, Linear mixed-effect model analysis, interaction of genotype and distance from soma, random effect of animal. $\boldsymbol{D}$, A trend toward decreased total basal dendritic length in Nex-cKO mice. $\boldsymbol{E}$, Similar total apical dendritic length between WT and Nex-cKO mice. $\boldsymbol{D}, \boldsymbol{E}$, Linear mixed-effect model analysis: fixed effect of genotype, random effect of animal. For all dendritic branching analysis, $n=22$ cells $/ 3$ mice for WT and $n=24$ cells $/ 4$ mice for Nex-cKO. Data are mean \pm SEM. ${ }^{*} p<0.05$.

properties and input-output properties of CA1 neurons in wildtype and Nex-cKO mice. We found no significant differences in the action potential threshold (linear mixed-effect model analysis: $F_{(1,5.87)}=0.4, p=0.551$; Fig. $7 A$ ), input resistance (linear mixed-effect model analysis: $F_{(1,5.97)}=0.73, p=0.427$; Fig. $\left.7 B\right)$, and an input-output curve correlating the amount of injected current to the number of action potentials (linear mixed-effect model analysis: $F_{(6,204.02)}=0.75, p=0.611$; Fig. $\left.7 C\right)$, suggesting that CA1 neurons lacking CDKL5 are comparable to wild-type neurons in their intrinsic membrane properties and their ability to generate action potentials. Next, we investigated excitatory synaptic transmission by recording mEPSCs. In Nex-cKO mice, we found a significant reduction in mEPSC inter-event intervals (linear mixed-effect model analysis, interaction of genotype and cumulative frequency bin: $F_{(19,696)}=5.28, p=4.63 \times 10^{-12}$ ), which resulted in a trend toward increased overall mEPSC frequency (linear mixed-effect model analysis, fixed effect of genotype (Nex-cKO-WT): $0.58 \mathrm{~Hz}, F_{(1,3.08)}=9.57, p=0.052$; Fig. $8 B, C$ ), whereas mEPSC amplitude was unaltered (linear mixed-effect model analysis: $F_{(1,3.93)}=0.28, p=0.623$; Fig. $8 D, E)$.

Given the evidence supporting enhanced spontaneous excitatory synaptic activity in Nex-cKO mice, we next asked whether this change represented a specific enhancement of AMPA- or NMDA-dependent currents. To estimate the relative contributions of AMPA- and NMDA-dependent currents in the same neuron, we performed recordings of evoked EPSCs at holding potentials of -70 and $+40 \mathrm{mV}$ (Myme et al., 2003; Etherton et al., 2009, 2011a). Nex-cKO mice showed similar amplitudes of the AMPA- (Fig. 9A,C) and NMDA-dependent EPSC components of evoked EPSCs (linear mixed-effect model analysis, AMPA-EPSC: $F_{(1,5.16)}=0.27, p=0.625$; NMDA-EPSC: $F_{(1,4.65)}=$ $0.54, p=0.498$; Fig. $9 B, D)$. Importantly, the NMDA/AMPA ratio was unaltered in Nex-cKO mice (linear mixed-effect model analysis: $F_{(1,3.44)}=0.06, p=0.821$; Fig. $\left.9 E\right)$. These results suggest that the enhancement of excitatory synaptic activity in Nex-cKO mice is unlikely to be attributed to a specific change in ionotropic glutamate receptor subtype.

\section{Enhanced inhibitory synaptic activity in CA1 pyramidal neurons of Nex-cKO mice}

Imbalances in excitation/inhibition (E/I) are commonly found in mouse models of neurodevelopmental disorders and thought to underlie a range of pathologic phenotypes, including impaired learning and memory (Rubenstein and Merzenich, 2003; Yizhar et al., 2011; Bateup et al., 2013; Shcheglovitov et al., 2013; Kepecs and Fishell, 2014; Nelson and Valakh, 2015; Sahin and Sur, 2015). Given our findings of enhanced excitatory synaptic activity in Nex-cKO mice, we next investigated whether the excitatory neuron-specific loss of CDKL5 also affects inhibitory synaptic transmission. To assess inhibition, we performed whole-cell patch-clamp recordings of miniature IPSCs (mIPSCs) from CA1 pyramidal neurons in wild-type and Nex-cKO mice. To avoid the potential confound of depolarization-induced suppression of inhibition (Wilson and Nicoll, 2001) and other depolarizationinduced changes, we used a high-chloride internal solution that allowed the recording of mIPSCs at a voltage near the resting membrane potential of CA1 pyramidal neurons. We found that CA1 pyramidal neurons in Nex-cKO mice showed a significant reduction in mIPSC inter-event intervals (linear mixed-effect model analysis, interaction of genotype and cumulative frequency bin: $\left.F_{(19,656)}=2.32, p=0.001\right)$, which resulted in a trend toward increased mIPSC frequency (linear mixed-effect model analysis, fixed effect of genotype (Nex-cKO-WT): $0.792 \mathrm{~Hz}$, $F_{(1,3.5)}=7.83, p=0.057$; Fig. $\left.10 B, C\right)$, whereas mIPSC amplitude was unaltered (linear mixed-effect model analysis: $F_{(1,3.5)}=0.01$, $p=0.92$; Fig. $10 D, E)$, suggesting an enhancement in spontane- 
A

WT

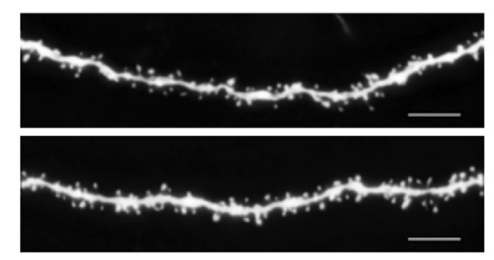

D

WT

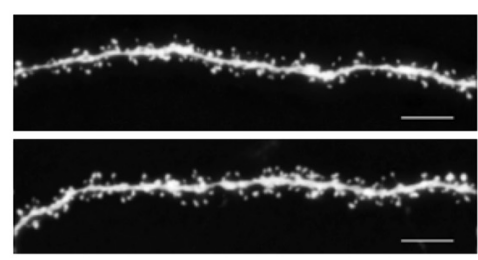

B Spine density - basal dendrites

\section{E Spine density - apical dendrites}
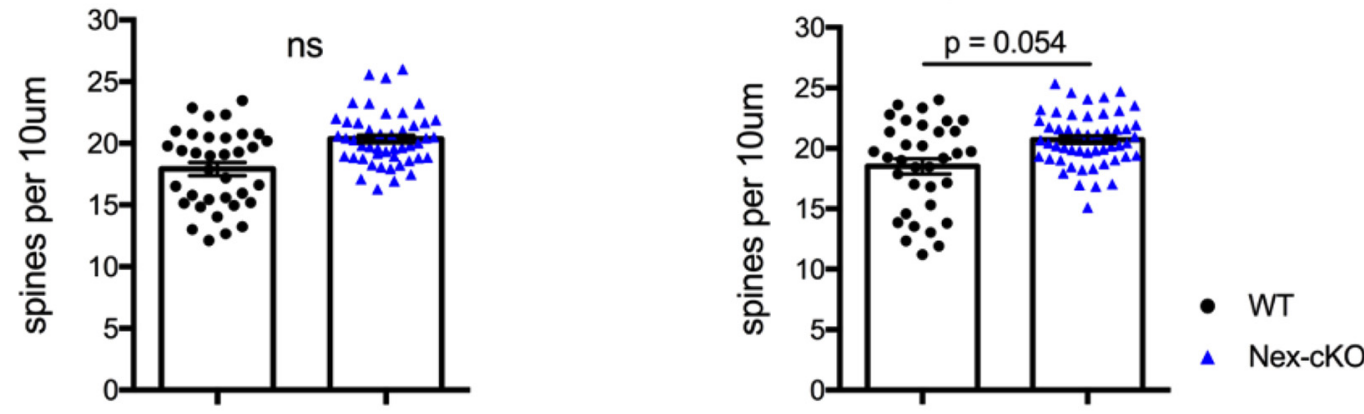

C

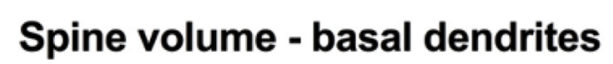

$\mathbf{F}$

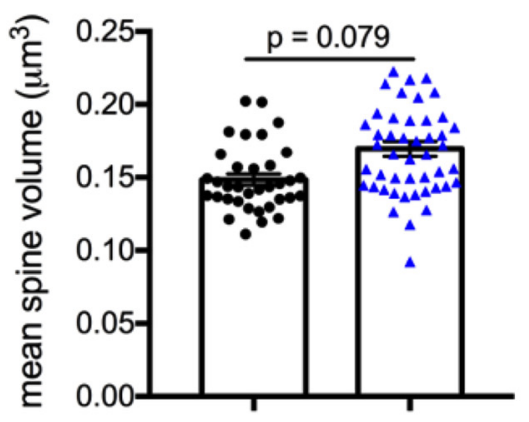

\section{Spine volume - apical dendrites}

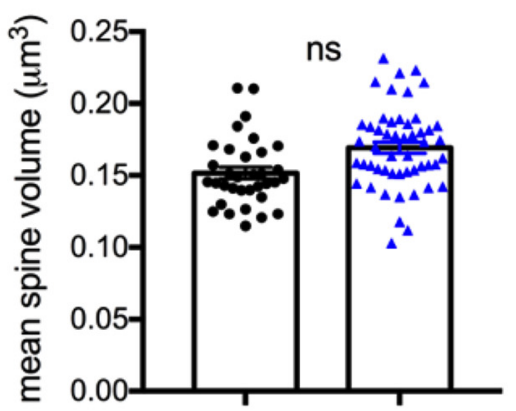

Figure 6. Analysis of spine density and morphology in CA1 pyramidal neurons of Nex-CKO mice. $A, D$, Representative segments from basal and proximal apical (excluding the apical tuft) dendrites of WT and Nex-CKO mice. Scale bar, $5 \mu \mathrm{m}$. B, Similar spine density at basal dendrites in Nex-CKO mice. $\boldsymbol{C}$, A trend toward increased spine volume at basal dendrites in Nex-cKO mice. $\boldsymbol{E}$, A trend toward increased spine density at proximal apical dendrites in Nex-cKO mice. $\boldsymbol{F}$, Similar spine volume at proximal apical dendrites in Nex-cKO mice. $\boldsymbol{B}, \boldsymbol{C}, \boldsymbol{E}, \boldsymbol{F}$, Linear mixed-effect model analysis, fixed effect of genotype, random effect of animal. For all spine analysis, one dendritic segment was imaged per cell. For basal dendritic spines, $n=35$ cells $/ 3$ mice for WT, $n=47$ cells $/ 3$ mice for Nex-cK0. For proximal apical dendritic spines, $n=34$ cells $/ 3$ mice for WT and $n=51$ cells $/ 3$ mice for Nex-cKO). Data are mean \pm SEM.

\section{A Spike threshold}

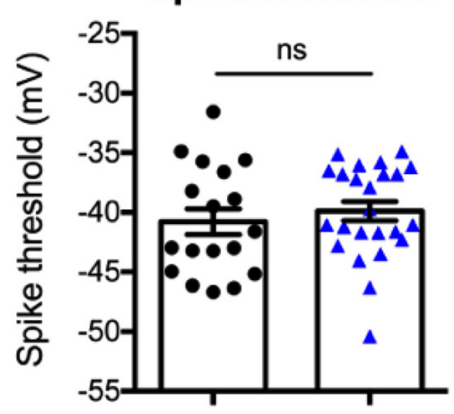

B Input resistance

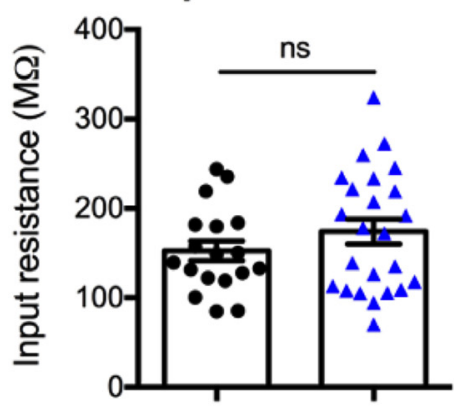

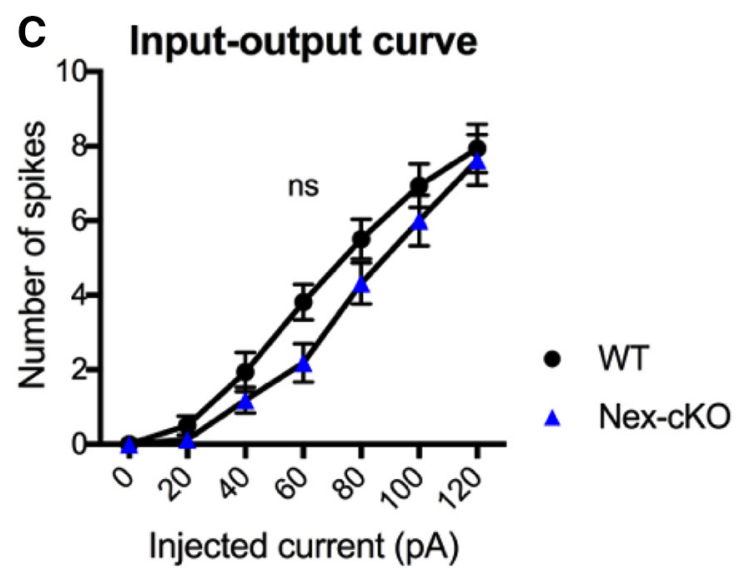

Figure 7. Unaltered intrinsic membrane properties in CA1 pyramidal neurons of Nex-cK0 mice. $\boldsymbol{A}$, Unaltered spike threshold in Nex-cKO mice. $\boldsymbol{B}$, Unaltered input resistance in Nex-cKO mice. $\boldsymbol{A}, \boldsymbol{B}$, Linear mixed-effect model analysis, fixed effect of genotype, random effect of animal. $\boldsymbol{C}$, Unaltered input- output curve in Nex-cK0 mice. For the input- output curve, incremental 300 ms current steps were applied, and the number of spikes was counted for each current amplitude. $\boldsymbol{C}$, Linear mixed-effect model analysis: interaction of genotype and current injected, random effect of animal. For all intrinsic membrane property experiments: $n=18$ cells $/ 4$ mice for WT and $n=24$ cells $/ 3$ mice for Nex-cKO. Data are mean \pm SEM. 
A
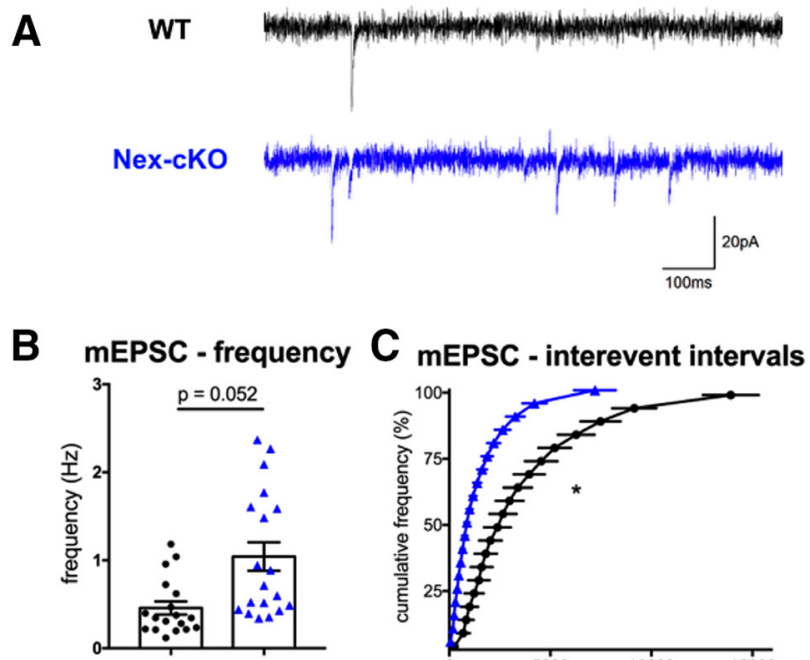

D

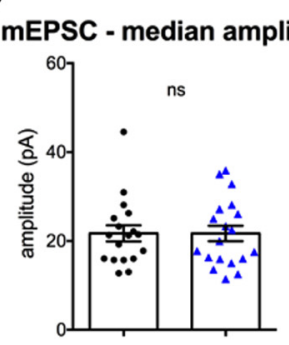

\section{C}
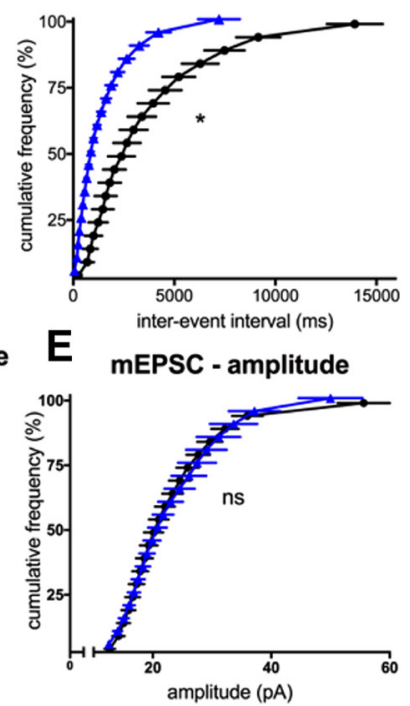

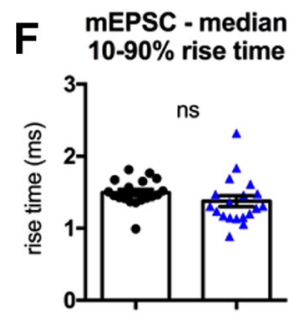

G mEPSC - median $90-10 \%$ decay time

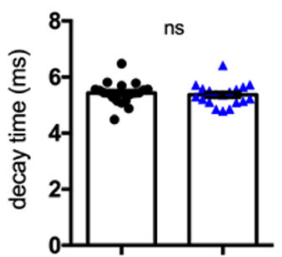

H MEPSC charge transfer rate

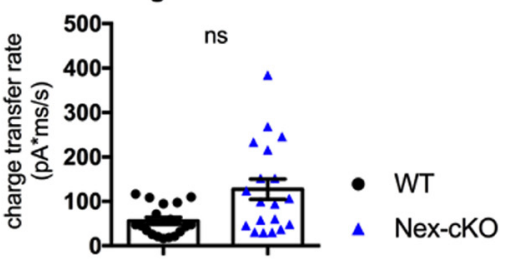

Figure 8. Increased mEPSC frequency in CA1 pyramidal neurons of Nex-CKO mice. A, Representative traces of mEPSCs recorded from WT and Nex-CKO mice. $\boldsymbol{B}, A$ trend toward increased frequency of $\mathrm{mEPSCS}$ in Nex-cKO mice. C, Decreased inter-event interval of mEPSCs in Nex-CKO mice. $\boldsymbol{D}, \boldsymbol{E}$, Unaltered mEPSC amplitude in Nex-cKO. $\boldsymbol{F}$, Unaltered mEPSC $10-90 \%$ rise time in Nex-cKO mice. G, Unaltered mEPSC $90-10 \%$ decay time in Nex-CKO mice. $\boldsymbol{H}$, Unaltered mEPSC charge transfer rate in Nex-CKO mice. $\boldsymbol{B}, \mathbf{D}, \boldsymbol{F}-\boldsymbol{H}$, Linear mixed-effect model analysis: fixed effect of genotype, random effect of animal. $C, E$, Linear mixed-effect model analysis: interaction of genotype and cumulative frequency bin, random effect of animal. For all $m E P S C$ analysis, one data point (WT, $m E P S C$ frequency $=3.95 \mathrm{~Hz}$ ) was eliminated in Grubb's test for outliers $(p<0.01) ; n=18$ cells $/ 3$ mice for WT and $n=19$ cells $/ 3$ mice for Nex-cK0. Data are mean \pm SEM. ${ }^{*} p<0.05$.

A

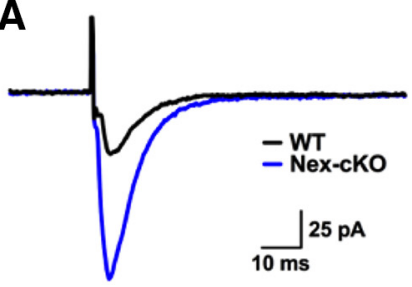

C

AMPA-EPSC

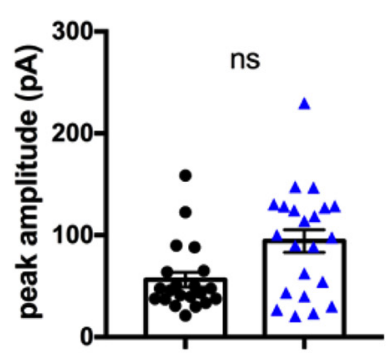

B

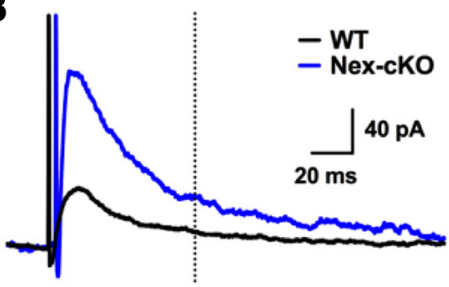

D

NMDA-EPSC

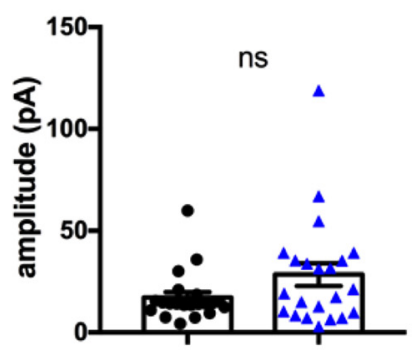

E NMDA/AMPA ratio

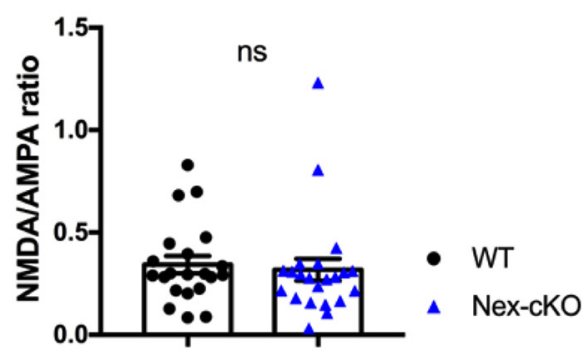

Figure 9. Unaltered AMPA/NMDA ratio in CA1 pyramidal neurons of Nex-cKO mice. $A$, Representative evoked AMPA-dependent EPSCs recorded at $-70 \mathrm{mV} . \boldsymbol{B}$, Representative evoked compound EPSCs recorded at $+40 \mathrm{mV}$. Dotted line indicates $75 \mathrm{~ms}$ poststimulus, a time point at which the AMPA-dependent contribution is considered negligible. C, Similar amplitudes of AMPA-dependent EPSCs recorded at $-70 \mathrm{mV}$. D, Similar amplitudes of NMDA-dependent component of EPSCS. $\boldsymbol{E}$, Unaltered NMDA/AMPA ratio in Nex-cKO mice. $\boldsymbol{C}-\boldsymbol{E}$, Linear mixed-effect model analysis: fixed effect of genotype, random effect of animal. One data point (WT: AMPA-EPSC $=305.1 \mathrm{pA}$ ) was eliminated in Grubb's test for outliers $(p<0.01) . n=21$ cells $/ 4$ mice for WT and $n=22$ cells $/ 4$ mice for Nex-cKO. Data are mean \pm SEM. 
A

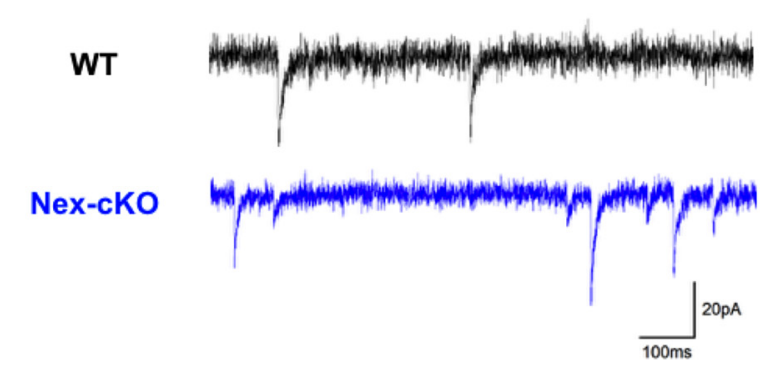

B

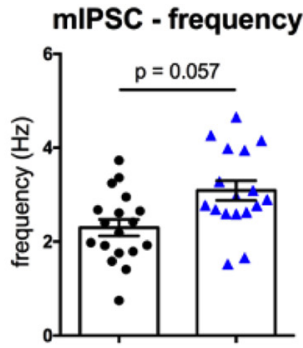

D mIPSC - median amplitude

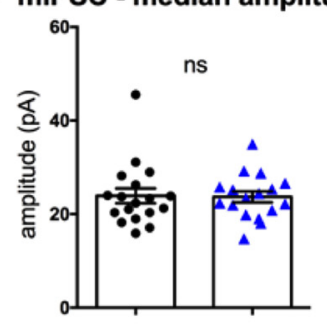

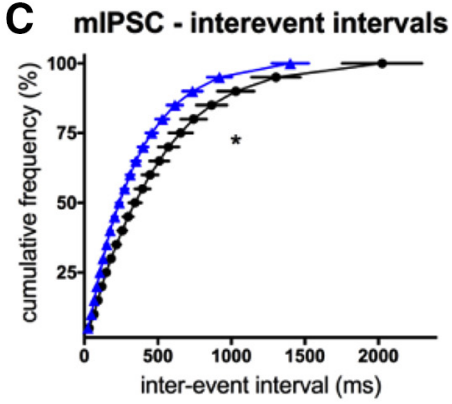

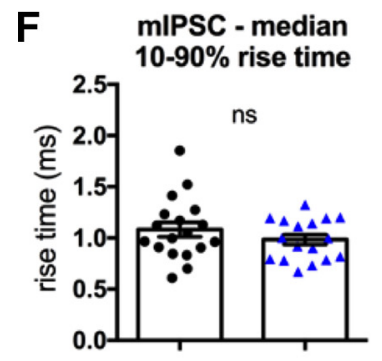

G

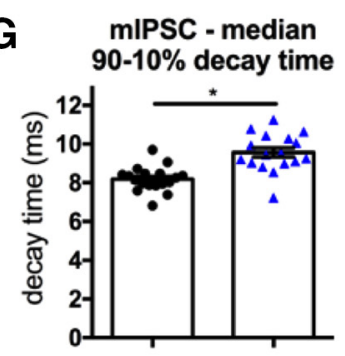

H mIPSC - charge transfer rate

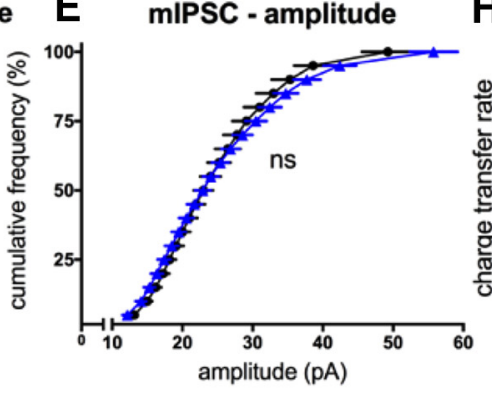

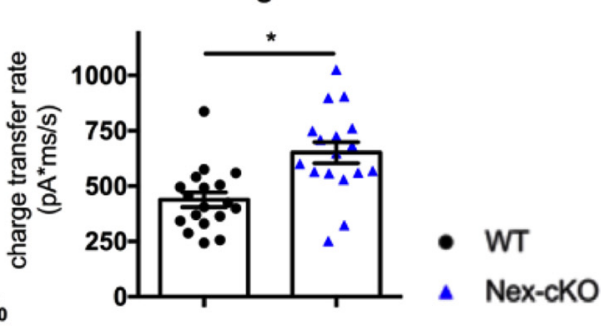

Figure 10. Increased mIPSC frequency in CA1 pyramidal neurons of Nex-CKO mice. $A$, Representative traces of mIPSCs recorded from WT and Nex-cK0 mice. $\boldsymbol{B}, A$ trend toward increased frequency of mIPSCs in Nex-cKO mice. C, Decreased inter-event interval of mIPSCs in Nex-cKO mice. D, E, Unaltered mIPSC amplitude in Nex-cKO mice. $\boldsymbol{F}$, Unaltered mIPSC $10-90 \%$ rise time in Nex-cKO mice. $\boldsymbol{G}$, Increased mIPSC $90-10 \%$ decay time in Nex-cK0 mice. $\boldsymbol{H}$, Increased mIPSC charge transfer rate in Nex-cKO mice. $\boldsymbol{B}, \boldsymbol{D}, \boldsymbol{F}-\boldsymbol{H}$, Linear mixed-effect model analysis: fixed effect of genotype, random effect of animal. $\boldsymbol{C}, \boldsymbol{E}$, Linear mixed-effect model analysis: interaction of genotype and cumulative frequency bin, random effect of animal. For all $\mathrm{mIPSC}$ analysis, $n=18$ cells $/ 3 \mathrm{mice}$ for WT and $n=17$ cells $/ 3$ mice for Nex-cKO. Data are mean \pm SEM. ${ }^{*} p<0.05$.

ous inhibitory synaptic activity onto pyramidal neurons. Intriguingly, we also found a significant increase in mIPSC decay time (linear mixed-effect model analysis, fixed effect of genotype (Nex-cKO-WT): $1.356 \mathrm{~ms}, F_{(1,3.74)}=17.2, p=0.016$; Fig. $\left.10 G\right)$. Together, the enhancement of mIPSC frequency and slowed decay kinetics in Nex-cKO mice contributed to a significantly enhanced inhibitory charge transfer rate (linear mixed-effect model analysis, fixed effect of genotype (Nex-cKO-WT): $213 \mathrm{pA} \cdot \mathrm{ms} / \mathrm{s}$, $F_{(1,3.5)}=12.86, p=0.029$; Fig. $\left.10 H\right)$. These results suggest that as a result of CDKL5 loss, CA1 pyramidal neurons in Nex-cKO mice show an enhancement of both spontaneous excitatory and inhibitory synaptic activity.

\section{Disrupted spatiotemporal dynamics of the CA1 microcircuit} in Nex-cKO mice

Our whole-cell patch-clamp studies revealed an elevation of both excitatory and inhibitory synaptic activity in Nex-cKO mice. An imbalance of excitation and inhibition, therefore, is not readily apparent from these findings alone. However, our whole-cell recordings assessed synaptic activity only at the soma and did not directly assess the spatiotemporal integration of excitation and inhibition occurring along the dendrites of pyramidal neurons. Given the distinct spatial distribution of excitatory and inhibitory synapses in the dendritic and somatic domains of CA1 pyramidal neurons (Bloss et al., 2016), increases in excitation and inhibition are not likely to "cancel out". Therefore, we next asked whether circuit function in Nex-cKO mice might be affected in a more complex manner. To investigate the contribution of synaptic changes to a behaviorally relevant circuit function, we investigated how CA1 pyramidal neurons respond to stimulation at the Schaffer collaterals, a source of monosynaptic excitatory input that is critical for learning and memory in vivo. We used voltagesensitive dye imaging (VSDI), a technique that allows the quantitative analysis of evoked excitatory and inhibitory responses across time and space (Carlson and Coulter, 2008; Coulter et al., 2011). To compare Schaffer-evoked responses in CA1 regions of wild-type and Nex-cKO mice, we normalized stimulus intensities based on the excitability of individual slices. No significant differences were found for the half-maximal stimulus intensities (linear mixed-effect model analysis: $F_{(1,6.27)}=1.1, p=0.332$ ) and the elicited presynaptic fiber volley amplitudes (linear mixedeffect model analysis: $\left.F_{(1,8.06)}=0.27, p=0.619\right)$ in WT and Nex-cKO mice, suggesting that comparable stimuli were used in our VSDI experiments (see Fig. 12F, G).

To fully assess both the magnitude and spatial spread of VSDI responses, we generated ROIs in the stratum radiatum (proximal apical dendritic layer) and stratum pyramidale/oriens (cell body and basal dendritic layer), both proximal and distal to the site of 

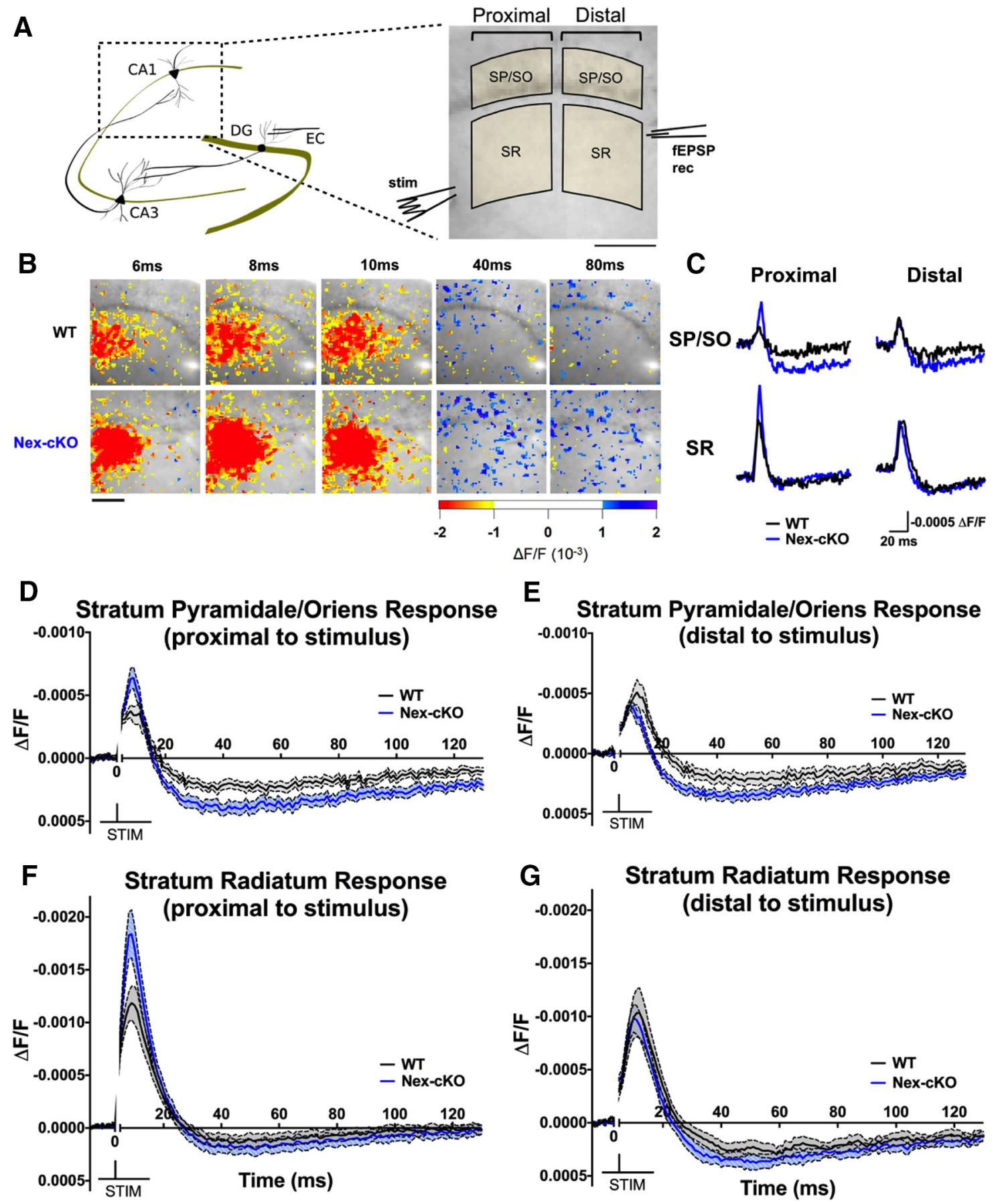

Figure 11. Disrupted spatiotemporal dynamics of the CA1 microcircuit in Nex-cKO mice. A, Schematic of VSDI showing the site of stimulation, site of field EPSP recording, and ROIs used for analysis. SR, Stratum radiatum; SP/SO, stratum pyramidale/oriens. Proximal and distal ROls were drawn for SR and SP/SO to assess the spatiotemporal spread of excitation and inhibition. $B$, Representative snapshots of Schaffer-evoked VSDI responses in WT and Nex-cKO mice. Depolarization is represented by warm colors, whereas hyperpolarization is represented by cool colors. Pixels with $\Delta F / F$ changes of $<1 \times 10^{-3}$ ( $\sim 3 \times$ the noise level) were blanked. Scale bars, $200 \mu \mathrm{m}$. C, Representative VSD responses in WT and Nex-cK0 mice in the proximal and distal SP/SO and SR. Following current-clamp convention, depolarization (decrease in $\Delta F / F$ ) is displayed as an upward signal, whereas hyperpolarization (increase in $\Delta F / F$ ) is displayed as a downward signal. A stimulus artifact occurring at $1-4$ ms poststimulation was removed. $\mathbf{D}-\boldsymbol{G}$, Averaged responses $(\Delta F / F)$ in stratum pyramidale/oriens $(\boldsymbol{D}, \boldsymbol{E})$ and stratum radiatum $(\boldsymbol{F}, \boldsymbol{G})$ of WT and Nex-cKO slices during the $130 \mathrm{~ms}$ immediately following Schaffer collateral stimulation. Note that excitation is enhanced in proximal, but not distal regions, whereas inhibition is enhanced primarily in the SP/SO. Error envelopes represent mean \pm SEM. For all experiments, $n=19$ slices $/ 7$ mice for WT and $n=18$ slices $/ 5$ mice for Nex-cKO.

stimulation (Fig. 11A). In wild-type mice, Schaffer collateral stimulation typically evokes a fast, temporally-restricted depolarization in stratum radiatum that is followed by a hyperpolarizing response in the stratum pyramidale/oriens (Fig. $11 B-D, F$ ), likely reflective of feedforward/feedback inhibition that is strongest in the perisomatic region (Pouille and Scanziani, 2001). In contrast,
Schaffer collateral stimulation in Nex-cKO mice led to a significantly enhanced depolarization in stratum radiatum in a region proximal to the stimulus (linear mixed-effect model analysis, interaction of genotype and time: $F_{(5,201.55)}=3.97, p=0.002$; generalized linear hypothesis tests with Holm's method to adjust for multiple comparisons, $8 \mathrm{~ms}: z=3.79, p=9.06 \times 10^{-4} ; 10$ 
A

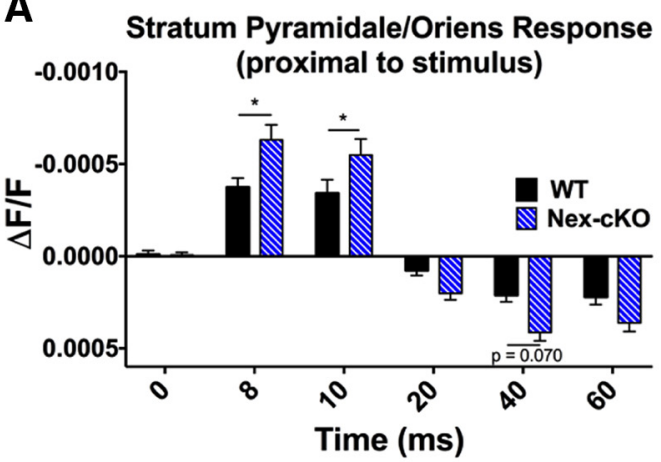

C

Stratum Radiatum Response (proximal to stimulus)

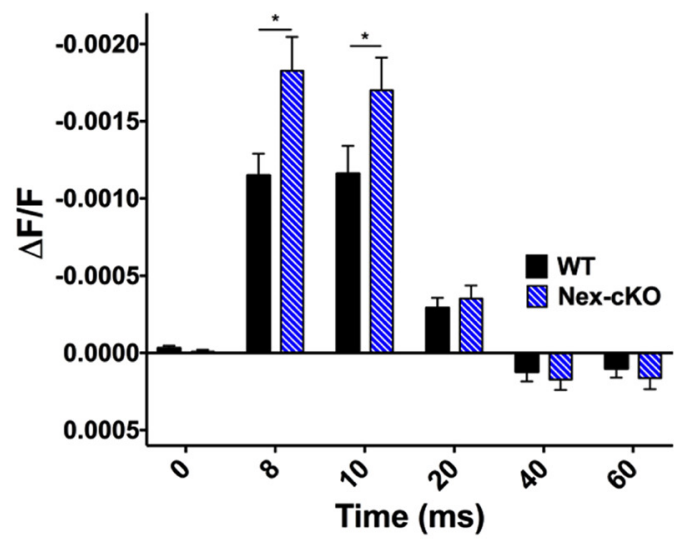

E

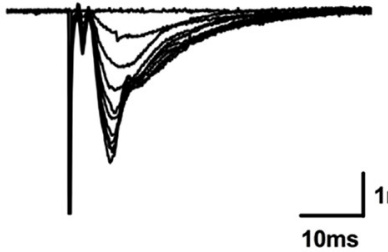

B
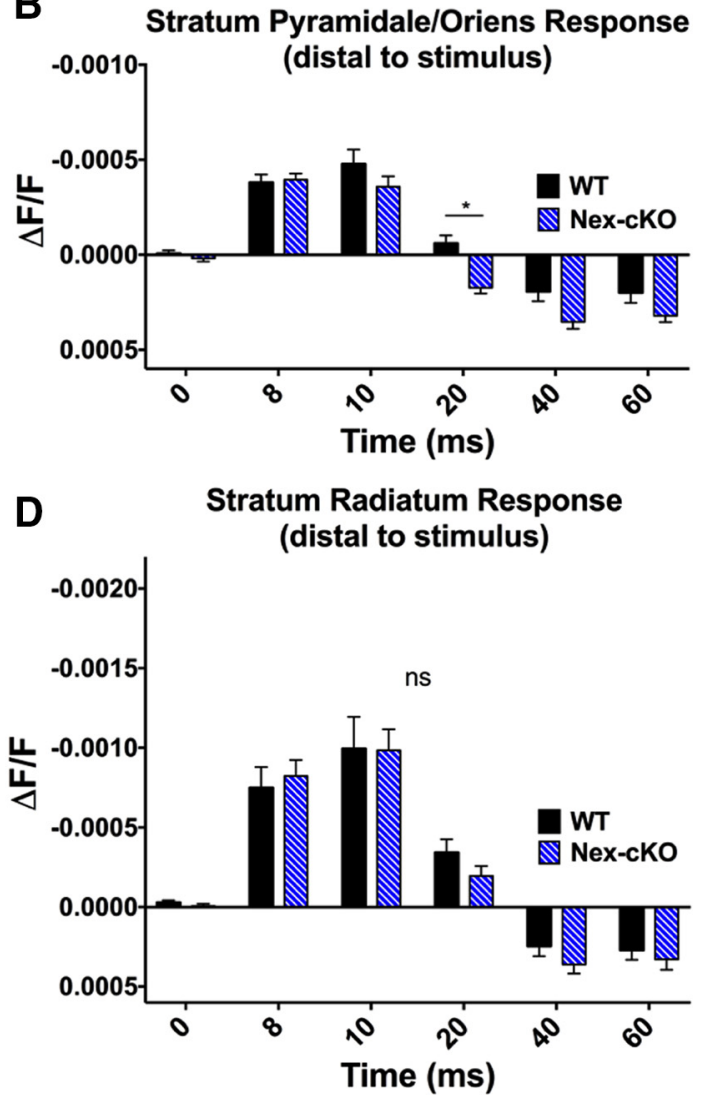

H

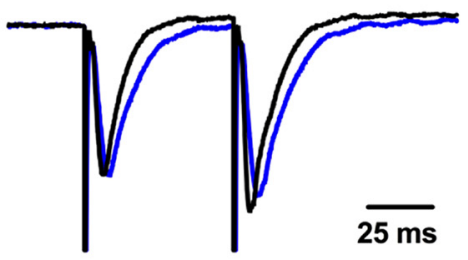

$\mathbf{F}$
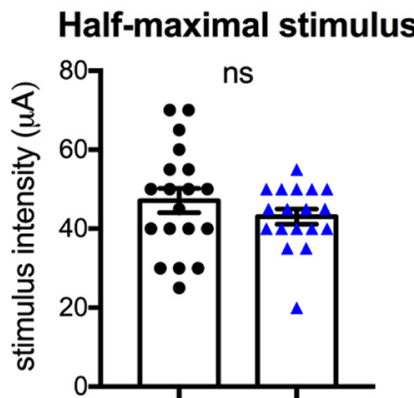

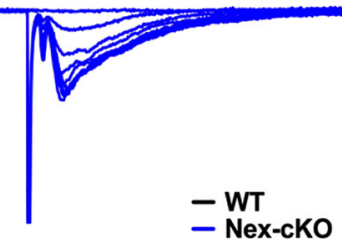

- Nex-cKo
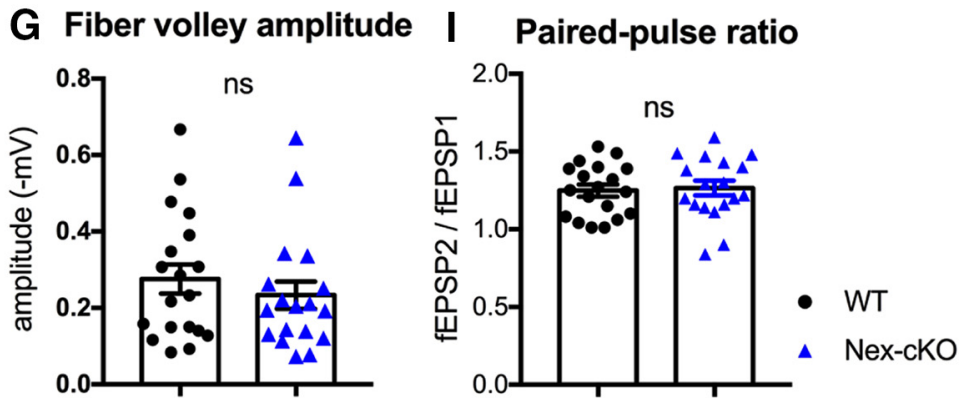

Figure 12. VSDI summary data, standardization of stimulus intensity, and paired-pulse ratio. $\boldsymbol{A}-\boldsymbol{D}$, Statistical comparisons of stratum pyramidale/oriens $(\boldsymbol{A}, \boldsymbol{B})$ and stratum radiatum $(\boldsymbol{C}, \boldsymbol{D})$ responses in WT and Nex-cKO mice at specific time points following stimulation. Note significantly enhanced excitation in Nex-cKO at $8-10$ ms poststimulus in proximal, but not distal, SR and SP/SO. Note significantly enhanced inhibition in Nex-CKO in the proximal and distal SP/SO at 40 and $20 \mathrm{~ms}$ poststimulus, respectively. $\boldsymbol{A}-\boldsymbol{D}$, Linear mixed-effect model analysis: interaction of genotype and time point, random effect of animal. Generalized linear hypothesis tests were performed for individual time points with Holm's method to adjust for multiple comparisons. $\boldsymbol{E}$, Representative Schaffer-evoked field EPSP traces in WT and Nex-CKO mice recorded at incremental stimulus intensity from 0 to $200 \mu$ a. The "half-maximal" stimulus intensity was defined as the stimulus required to elicit $\sim 50 \%$ of the maximal Schaffer-evoked field EPSP amplitude in stratum radiatum. $\boldsymbol{F}$, Standardized half-maximal stimulus intensities used for VSDI were not significantly different between WT and Nex-cKO mice. G, Fiber volley amplitudes elicited at half-maximal stimulus intensities were not significantly different between WT and Nex-cKO mice. $\boldsymbol{H}$, Representative paired-pulse fEPSP responses from WT and Nex-cKO mice, elicited at half-maximal stimulus intensity using a $60 \mathrm{~ms}$ interstimulus interval. $I$, Paired-pulse ratios of field EPSPs were not significantly different in WT and Nex-cKO mice. $\boldsymbol{F}-\mathbf{I}$, Linear mixed-effect model analysis: fixed effect of genotype, random effect of animal. For all experiments, $n=19$ slices $/ 7$ mice for WT and $n=18$ slices $/ 5$ mice for Nex-cK0. Data are mean \pm SEM. ${ }^{*} p<0.05$.

ms: $z=3.01, p=0.013$; Figs. $11 F, 12 C)$, demonstrating dendritic hyperexcitability consistent with the observed increase in spontaneous excitatory synaptic activity. Paired-pulse ratios from extracellular field recordings in the stratum radiatum were similar between wild-type and Nex-cKO mice (linear mixed-effect model analysis: $F_{(1,7.91)}=0.002, p=0.966$; Fig. $\left.12 I\right)$, suggesting that the observed dendritic hyperexcitability is unlikely to be of presynaptic origin, which is also consistent with previous findings local- 
WT

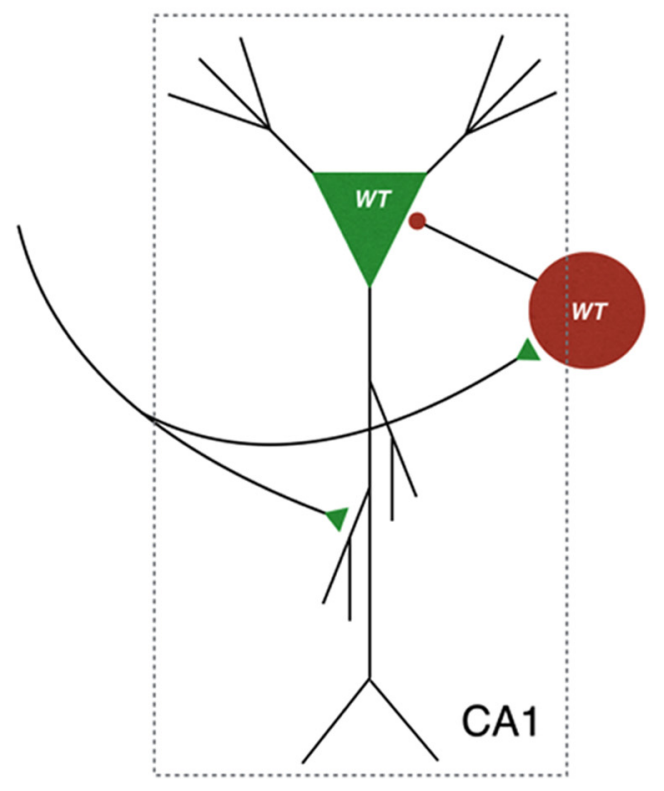

Nex-cKO

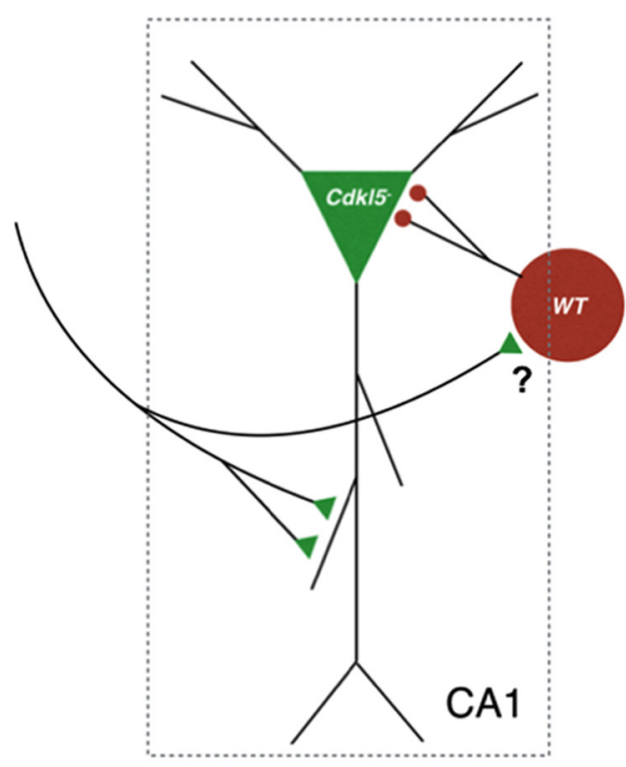

Figure 13. Model of synaptic and circuit abnormalities in Nex-cKO mice. In WT mice, the Schaffer collateral pathway predominantly activates excitatory synapses in the proximal dendrites (stratum radiatum) of CA1 pyramidal neurons. Activation of local interneurons leads to inhibition primarily in the cell body layer (stratum pyramidale). In mice lacking CDKL5 selectively in excitatory neurons, the concomitant upregulation of excitatory and inhibitory synaptic activity leads to exaggerated synaptic responses that alter the spatiotemporal dynamics of the CA1 microcircuit.

izing CDKL5 to the postsynaptic density (Ricciardi et al., 2012). Interestingly, in the stratum pyramidale/oriens of Nex-cKO mice proximal to the stimulus, we observed an enhancement of both depolarization and hyperpolarization (linear mixed-effect model analysis, interaction of genotype and time: $F_{(5,201.30)}=7.61, p=$ $1.42 \times 10^{-6}$; generalized linear hypothesis tests with Holm's method to adjust for multiple comparisons, $8 \mathrm{~ms}: z=3.28, p=$ $0.0062 ; 10 \mathrm{~ms}: z=2.66, p=0.039 ; 40 \mathrm{~ms}: z=-2.38, p=0.07$; Figs. $11 D, 12 A)$, suggesting an increase in perisomatic inhibition that is consistent with our finding of increased spontaneous inhibitory synaptic activity. However, in the stratum pyramidale/ oriens distal to the site of the stimulus, Nex-cKO mice showed only enhanced hyperpolarization (linear mixed-effect model analysis, of genotype and time: $F_{(5,201.20)}=2.25, p=0.051$; generalized linear hypothesis tests with Holm's method to adjust for multiple comparisons, $20 \mathrm{~ms}, z=-3.1, p=0.012$; Figs. $11 E, 12 B)$, suggesting that the spread of excitation is highly constrained in space by enhanced inhibition. Together, these results (1) confirm the dual enhancement of both excitatory and inhibitory synaptic activity identified in whole-cell recordings; and (2) show that, due to the differential spatial distribution of excitatory and inhibitory synapses, the dual enhancement does not "cancel out" but rather, alters the activation of the CA1 circuit in a spatially and temporally distinct manner (Fig. 13).

\section{Discussion}

In this study, we uncover the cellular origins of learning and memory impairment in a mouse model of CDKL5 deficiency through the generation of a forebrain excitatory neuron-specific Cdkl5 knock-out line (Nex-cKO). Nex-cKO mice demonstrate impaired hippocampal-dependent memory, along with contextdependent hyperactivity and hindlimb clasping. At the cellular level, we observe that altered neuronal morphology in Nex-cKO mice is accompanied by increased spontaneous excitatory and inhibitory synaptic activity, leading to altered spatiotemporal dynamics in the CA1 microcircuit that is relevant to learning and memory. Together, these findings reveal the glutamatergic origins of learning and memory impairment in CDKL5 deficiency and support a novel role for CDKL5 in regulating synaptic and circuit function in glutamatergic neurons.

We chose to focus on male hemizygous conditional knock-out mice to examine the role of CDKL5 in excitatory neurons, avoiding the potential confound introduced by random X-inactivation in heterozygous females, which leads to mosaic CDKL5 protein expression. However, because most patients with CDKL5 deficiency are female, future studies should aim to determine, in female heterozygous knock-out and conditional knock-out mice, the nature and extent of cellular and circuit abnormalities, and how these changes are affected by variable patterns of $\mathrm{X}$-inactivation. In this regard, the development of tools to discriminate $C d k l 5$ expression at cellular resolution in mosaic females will greatly facilitate the investigation of cellular and circuit endophenotypes and behavioral deficits.

\section{Disruption of hippocampal-dependent memory in Nex-cKO mice}

The finding of a relatively isolated deficit in hippocampaldependent memory in Nex-cKO mice suggests that these symptoms in CDKL5 deficiency likely have origins in the glutamatergic neuron, whereas other features likely arise from different cell types and associated circuits. These results point toward the value of a cell-type-specific approach to isolate the cellular signaling changes underlying CDKL5 deficiency-related phenotypes. For example, biochemical studies in Cdkl5 constitutive knock-out mice to date have focused on the cortex and hippocampus, regions where glutamatergic neuron types predominate (Hébert and Fishell, 2008; Poulin et al., 2016). Therefore, the changes in AKT-mTOR pathway activity (Wang et al., 2012; Amendola et al., 2014; Sala et al., 2016) and the phosphorylation of molecules such 
as GSK3 $\beta$ (Fuchs et al., 2014, 2015) and HDAC4 (Trazzi et al., 2016) reported likely represent the consequences of CDKL5 loss from glutamatergic neurons. Interestingly, pharmacologic treatment targeting these signaling changes appear to ameliorate learning and memory deficits in Cdkl5 constitutive knock-out mice (Fuchs et al., 2015; Trazzi et al., 2016), although other phenotypes have not yet been examined. Our findings confirm the importance of glutamatergic signaling in hippocampal-dependent learning and memory in CDKL5 deficiency, but suggest that other features of CDKL5 deficiency may arise from distinct cellular origins and may therefore involve distinct signaling pathways. Therefore, additional studies are necessary to determine the function of CDKL5 in other cell types, which may underlie symptoms such as reduced sociability, altered anxiety, and impaired motor coordination. For example, in the forebrain, where CDKL5 expression is enriched, GABAergic neurons constitute a second cell type that merits further investigation.

Similar to reports from $C d k l 5$ constitutive knock-out mice (Wang et al., 2012; Amendola et al., 2014), we did not find any evidence of spontaneous behavioral seizures in Nex-cKO mice. The contribution of genetic background to seizure susceptibility and differences in brain connectivity between humans and mice (Oh et al., 2014) are likely the cause. However, our results reveal a potential circuit-level mechanism for hyperexcitability, supporting a conserved role for CDKL5 in regulating the excitability of neuronal networks.

Altered CA1 pyramidal neuron morphology in Nex-cKO mice Our morphological studies reveal two sets of changes that stand in contrast to one another: reduced dendritic complexity and trends toward increased spine density and volume. One possibility is that the reduction in dendritic complexity is a secondary, homeostatic response to altered spine density and morphology and enhanced excitatory synaptic activity. Activity-dependent dendritic retraction is known to occur both in vivo and in vitro and has been documented in a model of Timothy syndrome involving a mutation in the voltage-gated calcium channel $\mathrm{Ca}_{\mathrm{V}} 1.2$ (Wong and Ghosh, 2002; Krey et al., 2013). Interestingly, elevated GSK-3 $\beta$ activity, which is associated with activity-dependent shrinkage of dendrites (Rui et al., 2013), has been found in mouse models of CDKL5 deficiency (Fuchs et al., 2014). The converse possibility, altered spine density and morphology being secondary to reduced dendritic complexity, seems less likely in the setting of an overall increase in excitatory synaptic activity in Nex-cKO mice. Because these contrasting findings typically do not accompany each other in models of neurodevelopmental disorders (Penzes et al., 2011), a third possibility is simply that CDKL5 regulates dendrite and synapse development through distinct mechanisms. This hypothesis may be consistent with recent findings in which neuronal activity in immature neurons leads to the induction of CDKL5 protein levels, whereas neuronal activity in mature neurons leads to the degradation of CDKL5 (La Montanara et al., 2015). CDKL5, therefore, may have distinct functions during stages of development that uniquely affects the processes of dendrite growth, spine generation, and activitydependent pruning. One such example of a family of kinases that serve two contrasting cellular functions is the doublecortin-like kinases (DLCKs), which promote dendrite growth but suppress synapse maturation (Shin et al., 2013).

\section{Altered synaptic inhibition in Nex-cKO mice}

Given that we selectively ablated CDKL5 expression from excitatory neurons, we were surprised to find altered inhibition in
Nex-cKO mice. CDKL5 has not been found to be localized at inhibitory synapses (Ricciardi et al., 2012), and it therefore may be tempting to conclude that the observed increase in inhibition in Nex-cKO is a compensatory response by GABAergic cells to mitigate $\mathrm{E} / \mathrm{I}$ balance. However, such compensatory changes in GABAergic synaptic activity do not typically accompany increased excitatory synaptic activity and circuit hyperexcitability in other animal models (Flavell et al., 2006; Chao et al., 2010; Luikart et al., 2011; Tsai et al., 2012; Bateup et al., 2013). A recent study in constitutive Cdkl5 knock-out mice discovered an upregulation of parvalbumin- and VGAT-positive puncta at the cell bodies of pyramidal neurons in the visual cortex (Pizzo et al., 2016). This finding is consistent with our results, which suggest an enhancement of perisomatic inhibition in the hippocampal CA1 region of NexcKO mice. Interestingly, our whole-cell recordings also revealed a significant enhancement of mIPSC decay time, potentially suggesting an alteration in the composition of $\mathrm{GABA}_{\mathrm{A}}$ receptor subunits (Goldstein et al., 2002). Therefore, it is possible that CDKL5 also regulates inhibitory synaptic function through a distinct mechanism that has yet to be discovered. For example, CDKL5 kinase activity may regulate the localization and function of postsynaptic scaffolding proteins such as gephyrin or subunits of the GABA receptor in excitatory neurons through post-translational modification.

\section{Disrupted microcircuit dynamics in Nex-cKO mice}

Our VSDI results suggest that the enhancement of excitatory and inhibitory synaptic activity do not neatly "cancel out". VSDI allowed the analysis of the spread of excitation and inhibition, capturing, in Nex-cKO mice, hyperexcitation that was spatiotemporally constrained by elevated inhibition (Figs. 11, 12). Given the interactions of the Schaffer collateral pathway with direct cortical input in vivo (Ang et al., 2005; Backus et al., 2016; Colgin, 2016), it is not surprising that such a circuit disturbance could underlie behavioral dysfunction. A prolonged Schafferevoked IPSP in Nex-cKO mice could impair oscillations across multiple frequency bands in vivo and have profound effects on neuronal firing patterns and synaptic plasticity, both of which could contribute to deficits in learning and memory.

Our findings emphasize the value of circuit profiling, particularly in models where multiple synaptic abnormalities are present. Given increasing evidence supporting the circuit specificity of neurophysiological findings in animal models (Etherton et al., 2011b; Qiu et al., 2011; Shepherd and Katz, 2011; DeNardo et al., 2012; O'Hare et al., 2016), targeted analysis of behaviorally relevant cell types and associated microcircuits are most likely to yield insight into the mechanisms responsible for pathological phenotypes. For example, a recent study found that the loss and gain of MeCP2 in mice led to convergent phenotypes of CA1 pyramidal neuron hypersynchrony (Lu et al., 2016). In addition, chronic forniceal deep-brain stimulation can rescue both impaired learning and memory and underlying circuit dysfunction across these multiple models of Rett syndrome (Hao et al., 2015; $\mathrm{Lu}$ et al., 2016), illustrating the potential of neural circuit studies to reveal avenues of therapy in disorders with diverse molecular etiologies. Our findings that CDKL5 plays an essential role in excitatory neurons to regulate hippocampal-dependent memory and circuit function suggest that in addition to therapies that seek to correct the underlying signaling changes, the modulation of circuit activity may also serve as a therapeutic target to ameliorate CDKL5 deficiency-associated learning and memory deficits. 


\section{References}

Amendola E, Zhan Y, Mattucci C, Castroflorio E, Calcagno E, Fuchs C, Lonetti G, Silingardi D, Vyssotski AL, Farley D, Ciani E, Pizzorusso T, Giustetto M, Gross CT (2014) Mapping pathological phenotypes in a mouse model of CDKL5 disorder. PLoS One 9:e91613-91712. CrossRef Medline

Ang CW, Carlson GC, Coulter DA (2005) Hippocampal CA1 circuitry dynamically gates direct cortical inputs preferentially at theta frequencies. J Neurosci 25:9567-9580. CrossRef Medline

Antić S, Zecević D (1995) Optical signals from neurons with internally applied voltage-sensitive dyes. J Neurosci 15:1392-1405. Medline

Arellano JI, Benavides-Piccione R, Defelipe J, Yuste R (2007) Ultrastructure of dendritic spines: correlation between synaptic and spine morphologies. Front Neurosci 1:131-143. CrossRef Medline

Backus AR, Schoffelen JM, Szebényi S, Hanslmayr S, Doeller CF (2016) Hippocampal-prefrontal theta oscillations support memory integration. Curr Biol 26:450-457. CrossRef Medline

Bahi-Buisson N, Bienvenu T (2012) CDKL5-related disorders: from clinical description to molecular genetics. Mol Syndromol 2:137-152. CrossRef Medline

Bates D, Mächler M, Bolker B, Walker S (2015) Fitting linear mixed-effects models using lme4. J Stat Softw 67:1-48. CrossRef

Bateup HS, Johnson CA, Denefrio CL, Saulnier JL, Kornacker K, Sabatini BL (2013) Excitatory/inhibitory synaptic imbalance leads to hippocampal hyperexcitability in mouse models of tuberous sclerosis. Neuron 78:510 522. CrossRef Medline

Bloss EB, Cembrowski MS, Karsh B, Colonell J, Fetter RD, Spruston N (2016) Structured dendritic inhibition supports branch-selective integration in CA1 pyramidal cells. Neuron 89:1016-1030. CrossRef Medline

Carlson GC, Coulter DA (2008) In vitro functional imaging in brain slices using fast voltage-sensitive dye imaging combined with whole-cell patch recording. Nat Protoc 3:249-255. CrossRef Medline

Cembrowski MS, Wang L, Sugino K, Shields BC, Spruston N (2016) Hipposeq: a comprehensive RNA-seq database of gene expression in hippocampal principal neurons. eLife 5:e14997. CrossRef Medline

Chao HT, Chen H, Samaco RC, Xue M, Chahrour M, Yoo J, Neul JL, Gong S, Lu HC, Heintz N, Ekker M, Rubenstein JL, Noebels JL, Rosenmund C, Zoghbi HY (2010) Dysfunction in GABA signalling mediates autismlike stereotypies and Rett syndrome phenotypes. Nature 468:263-269. CrossRef Medline

Chen Q, Zhu YC, Yu J, Miao S, Zheng J, Xu L, Zhou Y, Li D, Zhang C, Tao J, Xiong ZQ (2010) CDKL5, a protein associated with Rett syndrome, regulates neuronal morphogenesis via Rac1 signaling. J Neurosci 30:1277712786. CrossRef Medline

Colgin LL (2016) Rhythms of the hippocampal network. Nat Rev Neurosci 17:239-249. CrossRef Medline

Coulter DA, Yue C, Ang CW, Weissinger F, Goldberg E, Hsu FC, Carlson GC, Takano H (2011) Hippocampal microcircuit dynamics probed using optical imaging approaches. J Physiol 589:1893-1903. CrossRef Medline

Deacon RM (2006) Assessing nest building in mice. Nat Protoc 1:11171119. CrossRef Medline

DeNardo LA, de Wit J, Otto-Hitt S, Ghosh A (2012) NGL-2 regulates inputspecific synapse development in CA1 pyramidal neurons. Neuron 76: 762-775. CrossRef Medline

Etherton MR, Blaiss CA, Powell CM, Südhof TC (2009) Mouse neurexinlalpha deletion causes correlated electrophysiological and behavioral changes consistent with cognitive impairments. Proc Natl Acad Sci U S A 106:17998-18003. CrossRef Medline

Etherton MR, Tabuchi K, Sharma M, Ko J, Südhof TC (2011a) An autismassociated point mutation in the neuroligin cytoplasmic tail selectively impairs AMPA receptor-mediated synaptic transmission in hippocampus. EMBO J 30:2908-2919. CrossRef Medline

Etherton M, Földy C, Sharma M, Tabuchi K, Liu X, Shamloo M, Malenka RC, Südhof TC (2011b) Autism-linked neuroligin-3 R451C mutation differentially alters hippocampal and cortical synaptic function. Proc Natl Acad Sci U S A 108:13764-13769. CrossRef Medline

Fairless AH, Katz JM, Vijayvargiya N, Dow HC, Kreibich AS, Berrettini WH, Abel T, Brodkin ES (2013) Development of home cage social behaviors in BALB/cJ vs. C57BL/6J mice. Behav Brain Res 237:338-347. CrossRef Medline

Fehr S, Downs J, Ho G, de Klerk N, Forbes D, Christodoulou J, Williams S,
Leonard H (2016) Functional abilities in children and adults with the CDKL5 disorder. Am J Med Genet 170:2860-2869. CrossRef Medline

Feng G, Mellor RH, Bernstein M, Keller-Peck C, Nguyen QT, Wallace M, Nerbonne JM, Lichtman JW, Sanes JR (2000) Imaging neuronal subsets in transgenic mice expressing multiple spectral variants of GFP. Neuron 28:41-51. CrossRef Medline

Flavell SW, Cowan CW, Kim TK, Greer PL, Lin Y, Paradis S, Griffith EC, Hu LS, Chen C, Greenberg ME (2006) Activity-dependent regulation of MEF2 transcription factors suppresses excitatory synapse number. Science 311:1008-1012. CrossRef Medline

Fuchs C, Trazzi S, Torricella R, Viggiano R, De Franceschi M, Amendola E, Gross C, Calzà L, Bartesaghi R, Ciani E (2014) Loss of CDKL5 impairs survival and dendritic growth of newborn neurons by altering AKT/ GSK-3 $\beta$ signaling. Neurobiol Dis 70:53-68. CrossRef Medline

Fuchs C, Rimondini R, Viggiano R, Trazzi S, De Franceschi M, Bartesaghi R, Ciani E (2015) Inhibition of GSK3 $\beta$ rescues hippocampal development and learning in a mouse model of CDKL5 disorder. Neurobiol Dis 82: 298-310. CrossRef Medline

Goebbels S, Bormuth I, Bode U, Hermanson O, Schwab MH, Nave KA (2006) Genetic targeting of principal neurons in neocortex and hippocampus of NEX-Cre mice. Genesis 44:611-621. CrossRef Medline

Goldstein PA, Elsen FP, Ying SW, Ferguson C, Homanics GE, Harrison NL (2002) Prolongation of hippocampal miniature inhibitory postsynaptic currents in mice lacking the GABA(A) receptor alpha1 subunit. J Neurophysiol 88:3208-3217. CrossRef Medline

Habib-E-Rasul Mullah S, Komuro R, Yan P, Hayashi S, Inaji M, MomoseSato Y, Loew LM, Sato K (2013) Evaluation of voltage-sensitive fluorescence dyes for monitoring neuronal activity in the embryonic central nervous system. J Membr Biol 246:679-688. CrossRef Medline

Halekoh U, Højsgaard S (2014) A Kenward-Roger approximation and parametric bootstrap methods for tests in linear mixed models: the RPackage pbkrtest. J Stat Softw 59:1-32. CrossRef

Hao S, Tang B, Wu Z, Ure K, Sun Y, Tao H, Gao Y, Patel AJ, Curry DJ, Samaco RC, Zoghbi HY, Tang J (2015) Forniceal deep brain stimulation rescues hippocampal memory in Rett syndrome mice. Nature 526:430-434. CrossRef Medline

Harris KM, Stevens JK (1989) Dendritic spines of CAl pyramidal cells in the rat hippocampus: serial electron microscopy with reference to their biophysical characteristics. J Neurosci 9:2982-2997. Medline

Hébert JM, Fishell G (2008) The genetics of early telencephalon patterning: some assembly required. Nat Rev Neurosci 9:678-685. CrossRef Medline

Hothorn T, Bretz F, Westfall P (2008) Simultaneous inference in general parametric models. Biom J 50:346-363. CrossRef Medline

Johnson BS, Zhao Y, Fasolino MD, Lamonica J, Kim YJ, Georgakilas G, Wood KH, Bu D, Cui Y, Goffin D, Vahedi G, Kim TH, Zhou Z (2017) Biotin tagging of MeCP2 reveals contextual insights into the Rett syndrome transcriptome. Nat Med, in press.

Kalscheuer VM, Tao J, Donnelly A, Hollway G, Schwinger E, Kübart S, Menzel C, Hoeltzenbein M, Tommerup N, Eyre H, Harbord M, Haan E, Sutherland GR, Ropers HH, Gécz J (2003) Disruption of the serine/ threonine kinase 9 gene causes severe $\mathrm{X}$-linked infantile spasms and mental retardation. Am J Hum Genet 72:1401-1411. CrossRef Medline

Kenward MG, Roger JH (1997) Small sample inference for fixed effects from restricted maximum likelihood. Biometrics 53:983-997. CrossRef Medline

Kepecs A, Fishell G (2014) Interneuron cell types are fit to function. Nature 505:318-326. CrossRef Medline

Kilstrup-Nielsen C, Rusconi L, La Montanara P, Ciceri D, Bergo A, Bedogni F, Landsberger N (2012) What we know and would like to know about CDKL5 and its involvement in epileptic encephalopathy. Neural Plast 2012:728267-728311. CrossRef Medline

Krey JF, Paşca SP, Shcheglovitov A, Yazawa M, Schwemberger R, Rasmusson R, Dolmetsch RE (2013) Timothy syndrome is associated with activitydependent dendritic retraction in rodent and human neurons. Nat Neurosci 16:201-209. CrossRef Medline

La Montanara P, Rusconi L, Locarno A, Forti L, Barbiero I, Tramarin M, Chandola C, Kilstrup-Nielsen C, Landsberger N (2015) Synaptic synthesis, dephosphorylation, and degradation: a novel paradigm for an activity-dependent neuronal control of CDKL5. J Biol Chem 290:45124527. CrossRef Medline

Lein ES, Hawrylycz MJ, Ao N, Ayres M, Bensinger A, Bernard A, Boe AF, Boguski MS, Brockway KS, Byrnes EJ, Chen L, Chen L, Chen TM, Chin 
MC, Chong J, Crook BE, Czaplinska A, Dang CN, Datta S, Dee NR, et al. (2007) Genome-wide atlas of gene expression in the adult mouse brain. Nature 445:168-176. CrossRef Medline

Lu H, Ash RT, He L, Kee SE, Wang W, Yu D, Hao S, Meng X, Ure K, Ito-Ishida A, Tang B, Sun Y, Ji D, Tang J, Arenkiel BR, Smirnakis SM, Zoghbi HY (2016) Loss and gain of MeCP2 cause similar hippocampal circuit dysfunction that is rescued by deep brain stimulation in a rett syndrome mouse model. Neuron 91:739-747. CrossRef Medline

Luikart BW, Schnell E, Washburn EK, Bensen AL, Tovar KR, Westbrook GL (2011) Pten knockdown in vivo increases excitatory drive onto dentate granule cells. J Neurosci 31:4345-4354. CrossRef Medline

Myme CI, Sugino K, Turrigiano GG, Nelson SB (2003) The NMDA-toAMPA ratio at synapses onto layer $2 / 3$ pyramidal neurons is conserved across prefrontal and visual cortices. J Neurophysiol 90:771-779. CrossRef Medline

Nelson SB, Valakh V (2015) Excitatory/inhibitory balance and circuit homeostasis in autism spectrum disorders. Neuron 87:684-698. CrossRef Medline

Nimchinsky EA, Sabatini BL, Svoboda K (2002) Structure and function of dendritic spines. Annu Rev Physiol 64:313-353. CrossRef Medline

O'Hare JK, Ade KK, Sukharnikova T, Van Hooser SD, Palmeri ML, Yin HH, Calakos N (2016) Pathway-specific striatal substrates for habitual behavior. Neuron 89:472-479. CrossRef Medline

Oh SW, Harris JA, Ng L, Winslow B, Cain N, Mihalas S, Wang Q, Lau C, Kuan L, Henry AM, Mortrud MT, Ouellette B, Nguyen TN, Sorensen SA, Slaughterbeck CR, Wakeman W, Li Y, Feng D, Ho A, Nicholas E, et al. (2014) A mesoscale connectome of the mouse brain. Nature 508:207214. CrossRef Medline

Penzes P, Cahill ME, Jones KA, VanLeeuwen JE, Woolfrey KM (2011) Dendritic spine pathology in neuropsychiatric disorders. Nat Neurosci 14: 285-293. CrossRef Medline

Pizzo R, Gurgone A, Castroflorio E, Amendola E, Gross C, Sassoè-Pognetto M, Giustetto M (2016) Lack of Cdkl5 disrupts the organization of excitatory and inhibitory synapses and parvalbumin interneurons in the primary visual cortex. Front Cell Neurosci 10:261. CrossRef Medline

Pouille F, Scanziani M (2001) Enforcement of temporal fidelity in pyramidal cells by somatic feed-forward inhibition. Science 293:1159-1163. CrossRef Medline

Poulin JF, Tasic B, Hjerling-Leffler J, Trimarchi JM, Awatramani R (2016) Disentangling neural cell diversity using single-cell transcriptomics. Nat Neurosci 19:1131-1141. CrossRef Medline

Qiu S, Anderson CT, Levitt P, Shepherd GM (2011) Circuit-specific intracortical hyperconnectivity in mice with deletion of the autism-associated Met receptor tyrosine kinase. J Neurosci 31:5855-5864. CrossRef Medline

Ricciardi S, Ungaro F, Hambrock M, Rademacher N, Stefanelli G, Brambilla D, Sessa A, Magagnotti C, Bachi A, Giarda E, Verpelli C, Kilstrup-Nielsen C, Sala C, Kalscheuer VM, Broccoli V, et al. (2012) CDKL5 ensures excitatory synapse stability by reinforcing NGL-1-PSD95 interaction in the postsynaptic compartment and is impaired in patient iPSC-derived neurons. Nat Cell Biol 14:911-923. CrossRef Medline

Rubenstein JL, Merzenich MM (2003) Model of autism: increased ratio of excitation/inhibition in key neural systems. Genes Brain Behav 2:255267. CrossRef Medline

Rui Y, Myers KR, Yu K, Wise A, De Blas AL, Hartzell HC, Zheng JQ (2013) Activity-dependent regulation of dendritic growth and maintenance by glycogen synthase kinase $3 \beta$. Nat Commun 4:2628. CrossRef Medline

Rusconi L, Salvatoni L, Giudici L, Bertani I, Kilstrup-Nielsen C, Broccoli V, Landsberger N (2008) CDKL5 expression is modulated during neuronal development and its subcellular distribution is tightly regulated by the C-terminal tail. J Biol Chem 283:30101-30111. CrossRef Medline

Sahin M, Sur M (2015) Genes, circuits, and precision therapies for autism and related neurodevelopmental disorders. Science 350: aab3897. CrossRef Medline

Sala Della G, Putignano E, Chelini G, Melani R, Calcagno E, Michele Ratto G, Amendola E, Gross CT, Giustetto M, Pizzorusso T (2016) Dendritic spine instability in a mouse model of CDKL5 disorder is rescued by insulin-like growth factor 1. Biol Psychiatry 80:302-311. CrossRef Medline

Sankoorikal GM, Kaercher KA, Boon CJ, Lee JK, Brodkin ES (2006) A mouse model system for genetic analysis of sociability: C57BL/6J versus $\mathrm{BALB} / \mathrm{cJ}$ inbred mouse strains. Biol Psychiatry 59:415-423. CrossRef Medline

Shcheglovitov A, Shcheglovitova O, Yazawa M, Portmann T, Shu R, Sebastiano V, Krawisz A, Froehlich W, Bernstein JA, Hallmayer JF, Dolmetsch RE (2013) SHANK3 and IGF1 restore synaptic deficits in neurons from 22q13 deletion syndrome patients. Nature 503:267-271. CrossRef Medline

Shepherd GM, Katz DM (2011) Synaptic microcircuit dysfunction in genetic models of neurodevelopmental disorders: focus on Mecp2 and Met. Curr Opin Neurobiol 21:827-833. CrossRef Medline

Shin E, Kashiwagi Y, Kuriu T, Iwasaki H, Tanaka T, Koizumi H, Gleeson JG, Okabe S (2013) Doublecortin-like kinase enhances dendritic remodelling and negatively regulates synapse maturation. Nat Commun 4:1440. CrossRef Medline

Trazzi S, Fuchs C, Viggiano R, De Franceschi M, Valli E, Jedynak P, Hansen FK, Perini G, Rimondini R, Kurz T, Bartesaghi R, Ciani E (2016) HDAC4: a key factor underlying brain developmental alterations in CDKL5 disorder. Hum Mol Genet 25:3887-3907. CrossRef Medline

Tsai PT, Hull C, Chu Y, Greene-Colozzi E, Sadowski AR, Leech JM, Steinberg J, Crawley JN, Regehr WG, Sahin M (2012) Autistic-like behaviour and cerebellar dysfunction in Purkinje cell Tsc1 mutant mice. Nature 488: 647-651. CrossRef Medline

Wang IT, Allen M, Goffin D, Zhu X, Fairless AH, Brodkin ES, Siegel SJ, Marsh ED, Blendy JA, Zhou Z (2012) Loss of CDKL5 disrupts kinome profile and event-related potentials leading to autistic-like phenotypes in mice. Proc Natl Acad Sci U S A 109:21516-21521. CrossRef Medline

Weaving LS, Christodoulou J, Williamson SL, Friend KL, McKenzie OL, Archer H, Evans J, Clarke A, Pelka GJ, Tam PP, Watson C, Lahooti H, Ellaway CJ, Bennetts B, Leonard H, Gécz J (2004) Mutations of CDKL5 cause a severe neurodevelopmental disorder with infantile spasms and mental retardation. Am J Hum Genet 75:1079-1093. CrossRef Medline

Wilson RI, Nicoll RA (2001) Endogenous cannabinoids mediate retrograde signalling at hippocampal synapses. Nature 410:588-592. CrossRef Medline

Wong RO, Ghosh A (2002) Activity-dependent regulation of dendritic growth and patterning. Nat Rev Neurosci 3:803-812. CrossRef Medline

Yang M, Crawley JN (2009) Simple behavioral assessment of mouse olfaction. Curr Protoc Neurosci Jul:Chapter 8:Unit 8.24. CrossRef Medline

Yizhar O, Fenno LE, Prigge M, Schneider F, Davidson TJ, O'Shea DJ, Sohal VS, Goshen I, Finkelstein J, Paz JT, Stehfest K, Fudim R, Ramakrishnan C, Huguenard JR, Hegemann P, Deisseroth K (2011) Neocortical excitation/inhibition balance in information processing and social dysfunction. Nature 477:171-178. CrossRef Medline

Zhu YC, Li D, Wang L, Lu B, Zheng J, Zhao SL, Zeng R, Xiong ZQ (2013) Palmitoylation-dependent CDKL5-PSD-95 interaction regulates synaptic targeting of CDKL5 and dendritic spine development. Proc Natl Acad Sci U S A 110:9118-9123. CrossRef Medline 